\title{
On Dinosaur Reconstruction: Posture of Dinosaurs
}

\author{
Georgios A. Florides $\mathbb{Q}^{\circ}$, Paul Christodoulides \\ Faculty of Engineering and Technology, Cyprus University of Technology, Limassol, Cyprus \\ Email: paul.christodoulides@cut.ac.cy
}

How to cite this paper: Florides, G.A. and Christodoulides, P. (2021) On Dinosaur Reconstruction: Posture of Dinosaurs. Open Journal of Geology, 11, 756-793. https://doi.org/10.4236/ojg.2021.1112037

Received: November 13, 2021

Accepted: December 28, 2021

Published: December 31, 2021

Copyright (C 2021 by author(s) and Scientific Research Publishing Inc. This work is licensed under the Creative Commons Attribution International License (CC BY 4.0).

http://creativecommons.org/licenses/by/4.0/

\begin{abstract}
Dinosaurs due to their diverse species and peculiar forms have drawn the interest of both artists and scientists. One way to unlock the unknown life of dinosaurs is to reconstruct dinosaurs through drawings, computer animations or sculptures. Following the Introduction on "Dinosaur Reconstruction" by the present authors, where important Paleontological knowledge was presented, the next step is to examine some specific information along with necessary details for dinosaur reconstruction. The first and basic step to be taken for a reconstruction is the posture of the animal; this is the theme of the current paper. Dinosaurs would move either bipedally or quadrupedally depending on their kind and body construction. Based on the available literature, various issues in relation to the posture of an animal at different instances are examined. These are: postures of bipedal dinosaurs during walking, observation of living bipedal animals, postures of quadruped dinosaurs during walking, feeding styles, and dinosaur tails. Theropods had a locomotor behavior like modern birds, with the step width increasing when the animals decreased speed. The general posture and movement of quadrupeds and especially sauropods, remains a subject of great and much controversy. Some scientists believe that sauropod necks were generally held in a neutral or undeflected state during most of the time, while others believe that sauropod necks behaved like all present-day amniote with the mid-cervical region held nearly vertical. Also, there are indications that dinosaurs usually held their tails above ground. For all dinosaurs, the long tail was acting as a counterbalance to the head and body. As a validating example, the case of Amargasaurus is investigated with the help of a model, where the various positions of the animal are examined. A certain posture was chosen for a full-size steel and concrete reconstruction based on the features of the animal.
\end{abstract}

\section{Keywords}

Theropod Locomotion, Sauropod Locomotion, Dinosaur Postures, Necks and 
Tails, Extinct Animals, Skeletal Reconstruction, Dinosaur Modeling, Amargasaurus

\section{Introduction}

This is the second (after the Introduction [1]) in a series of articles that presents the theoretical background on important Paleontological knowledge that will enable one to reconstruct Dinosaurs in all scientific details. As an example, the series will demonstrate in detail the reconstruction steps of a specific Dinosaur, in full scale, that of Amargasaurus. The articles are written in a way that is comprehensible not only by specialists but also by the broader reader. Hence, the series can motivate people to interact with the Art of Paleontology and promote the understanding of past life on earth.

This, and the following parts (articles), will examine individual details and give specific information of dinosaur reconstruction. The first and basic decision that must be taken for a reconstruction is the posture of the animal. Specifically, the present article presents a number of general studies dealing with posture issues, with a specific example for Amargasaurus reconstruction given at the end.

Dinosaurs were animals that hunted or were hunted, displayed themselves, fought, walked, ran, stood still or sat down and of course interacted with their environment in many other ways. Therefore, scientists and artists have great varieties of postures from which they can choose to present a Dinosaur either for mounting a skeleton in a museum or producing a sculpture or painting. Once the posture is decided, in the case of mounting a skeleton or producing a sculpture, other parameters need to be accounted for. Such parameters are the weight of the construction material, the stability of the posture and easiness of forming. Because of the large size and weight of actual bones, museums prefer to mount duplicates mainly made of polyurethane or fiberglass that are light and durable, and because they can easily be processed and formed, compared to other materials.

The general posture and movement of dinosaurs is a subject of great interest and, besides the many angles by which it is tackled, there is still much controversy. Dinosaurs would move either bipedally or quadrupedally.

Farlow et al. [2] mention that bipedal dinosaurs (the theropods) vary in size from that of a chicken to that of an elephant. All of the theropods walked in an erect stance stepping on their digits with the posterior of the foot not touching the ground and in strides. The way these dinosaurs moved was affected by changes in the hip, tail and hindlimb. Evidence from trackways shows that non-avian theropods usually walked, and rarely used faster gaits. It is also assumed that smaller relatives were swifter than larger theropods.

Since theropod dinosaurs were bipedal, it is believed that understanding the locomotion of their modern descendants, the birds, a better understanding of 
their locomotion is accomplished. Living birds with their center of mass well anterior to the hip, keep the femur almost horizontal in order to balance. Following this observation and since bipedal dinosaurs had long tails, it is expected that their center of mass would move posteriorly and therefore, in order to balance at mid stance, their foot should be under the center of mass. This would mean that dinosaurs walked with their femurs closer to vertical than birds [3]. To demonstrate the above and show that non-avian theropods limb movement was driven by femur retraction in contrast to bird locomotion that is driven by knee flexion, Grossi et al. [4] performed an experiment. They examined raised chicken wearing artificial tails, thus moving the center of mass posteriorly. In this way, it was possible to recreate the posture and kinematics inferred for non-avian bipedal dinosaurs.

Tarsitano [5] recreated the theropod dinosaur, Tyrannosaurus rex, during a walking gait, by comparing the functional morphology of theropods to the locomotory systems of present-day lizards, crocodilians and birds. The results show a muscle pattern more similar to crocodilians than the other taxa.

Carrier et al. [6] examined the effect of the rotational inertia on the turning agility of theropods. Their results imply that the turning agility of theropods may have been largely limited by their trunks and tails. They conclude that when theropods were running, they kept an arched back and tail, an S-curved neck and with their forelimbs held backward against the body. Bishop et al. [7] used the ichnological and comparative biomechanical data to examine the locomotion of theropods. They found that when the animals increased speed, the step width decreased. Also, they observed that the theropod step width decreased gradually with speed, showing a continuous locomotor behavior similar to modern birds.

The quadrupedal dinosaurs belong to the order of ornithischia and saurischia. Sauropod dinosaurs have long necks and tails, a rather massive and heavy trunk and four pillar-like limbs. However, comparison between the sauropods shows that there are species with very large necks like Diplodocus and Brachiosaurus and those with shorter necks like Camarasaurus and Dicraeosaurus. There are also large differences among sauropods in tail length. These and other differences make it difficult for the scientists to reconstruct the postures of sauropods, which is a subject of much controversy. Osteologically the cervical vertebrae, can be articulated in various sensible ways, that may result in considerable changes in neck posture. For this reason, many other methods are employed for estimating the correct posture restoration of sauropods. Christian [8] analyses the neck intervertebral discs in regard to the forces and torques that they could sustain and estimates the range of possible postures (and gaits) of the animals. He suggests that Brachiosaurus brancai kept a nearly vertical neck posture (which is also attested by its overall skeletal design), with other postures been kept for only short time intervals. Diplodocus carnegii and Dicraeosaurus hansemanni kept the neck at low or medium levels. In this way, they could sweep over a large feeding area utilizing their long tail as a counterweight to balance, especially 
when the neck was moved sideways. A similar analysis for Mamenchisaurus youngi indicates that the neck during locomotion was kept in a rather straight or slightly inclined pose [9]. The foremost neck section was relatively more mobile than the posterior section. When standing at rest or in an alert position, the neck would be raised to 30 or 40 degrees.

Stevens [10] examined the neck flexibility of sauropods as inferred by osteological, missing soft tissue, intervertebral flexibility and behavioral terms. The results show that, contrary to the popular depictions showing avian flexibility of the necks (like a swan), the movement was restricted. The sauropod neck and dorsal vertebral column was essentially straight with not much flexibility. Sauropods could sweep over large feeding areas but were not able to retract the head for exploring the bounded volume in an avian manner. At rest and motion, the sauropod default head height was generally the undeflected neck height. In this position (the osteological neutral pose) the muscles are relaxed and there are less stresses.

Researchers have assumed that a way to find the head position at rest of extinct animals, was to study the plane of the lateral semicircular canal of the inner ear (see discussion on "Head Posture" in [11] and references therein). At the rest position the plane was assumed to be horizontal. In a recent study Benoit et al. [12] tested this assumption, which was repeatedly questioned, on a large sample size. The results show a statistically important correlation, but with the plane of the lateral semicircular canal departing from the horizontal position in a significant extent. Other factors, like diet habits (browsing or grazing) and head-butting behavior, show also important correlation and thus caution is needed when this method is used to infer the head position at rest of extinct animals.

Taylor et al. [13], after studying the present-day amniote groups, believe that sauropods were not an exception and did not keep their neck in an osteological neutral pose, as mentioned above. They believe that, as the extant (existing today) amniote, sauropods should usually hold their necks extended (in stress) and their heads flexed and with possibly the mid-cervical region in a rather vertical position. The necks were much more flexible and this can also be attested by the absence of osteological features that limit the neck flexibility. Concerning the results from the inclination of the semi-circular canals, they also believe that the results are untrusty because extant animals show a large variation in their orientation. Only a general idea of the life posture of the heads of extinct animals can be gained from this structure.

Wedel [14] examines complex features found on sauropod vertebrae and correlates them to the skeletal pneumatization of extant birds. More complex internal structures, found in the axial column of mamenchisaurs, diplodocids, brachiosaurids and some titanosaurians, are explained in correlation to increasing body size and neck length. The pneumatization of the vertebrae implies the presence of air sacs in sauropods, possibly not as complex and extensive as those 
of birds

Paul [15] believes that it is not possible to correctly restore the posture and range of motion in long necked dinosaurs because of illustration errors, distortion of the relevant fossil cervicals and absence of the intercentra cartilage. $\mathrm{He}$ also mentions that the existence of a single "neutral posture" in sauropods and its association to feeding habits is possibly wrong. He makes the assumption that if high browsing was not advantageous or there were circulatory reasons not allowing enough brain oxygenation when the head was raised considerably higher above the heart, then adaptations would not allow them to happen. This would result in short necks, osteological stops preventing long necks from being raised well above the shoulders, and absence of skeletal adaptations for rearing, which are not true.

Another line of evidence for postures and feeding habits is the study of the vertebral ligament. Generally, sauropods with bifurcated and non-bifurcated neural spines have been widely restored in the same way. The presence of bifurcated neural spines osteologically indicates different vertebral functions. Woodruff [16], based on extant taxa, suggests that the bifurcated neural spines of diplodocids may have been fed with a split nuchal ligament. This mechanism could well provide evidence for horizontal neck posture and lateral sweep feeding in diplodocid sauropods.

Of course, a rich and important source of information of Dinosaur types, sizes, locomotion, habits, etc. is the study of their tracks. Many studies refer to this subject as for example [16] [17] [18] [19] that give invaluable details of the animals that produced the prints.

In order to allow one to decide about the correct posture attained by an animal at different instances, the current study examines in more detail the following: postures of bipedal dinosaurs during walking, observation of living bipedal animals, postures of quadruped dinosaurs during walking, feeding styles, and dinosaur tails. Finally, for a better comprehension of the above research scope, in the form of an example, possible postures that Amargasaurus would display, according to theory, are examined for a full-size reconstruction in steel and concrete. A short description of the animal is given and, with the help of a small model, its posture is chosen.

\section{Materials and Methods}

Before trying to reconstruct any extinct animal, one must obtain the useful information about the animal's remains from relevant papers and books available in the literature. This is necessary in order to gain insight into the animal's behavior (posture, movement, growth, feeding, reproduction) and to appreciate the extinct environments in which the animal spent its life.

The current work presents paleontological topics that are found in the literature related to the possible postures and movements a dinosaur body could hold during its life. The first step toward bringing to life a dinosaur is to determine 
the posture that will be adopted for the reconstruction. In particular the following themes are studied in detail: evidence from tracks, evidence from bones and observation of living animals.

To keep the paper handy and informative, the focus is on knowledge found in basic books of general Paleontology, as well as knowledge found in journal articles for updated material. For offering further information to the reader, images from museums and freely available in the Web scientific articles are also included.

In order to alert the reader, the paper gives details for certain information in the literature that has been questioned or has been the subject of non-general consensus. Many questions in Paleontology remain open, but the gaps narrow as new information comes to light with new findings and new tools and methods that technology provides.

\section{Postures of Bipedal Dinosaurs during Walking}

\subsection{Evidence from Tracks}

Detailed movements of trackmakers can be studied from the evidence of tracks. The distance between successive prints of the animal's left and right feet (the pace), and the distance between two successive footprints of the same foot (the stride) obviously shows how the animal was moving (Figure 1); the longer the animal's steps, the more quickly it was moving. The extent to which left and right footprints of the animal are aligned, or widely separated from one another, may indicate how wide-bodied or narrow-bodied the trackmaker was, and whether it had an erect or sprawling carriage. The angle made by the longest dimension of the footprint with respect to the animal's direction of travel indicates whether the trackmaker walked with its feet angling outward or pointed straight ahead, or with its toes turned inward [20].

Additionally, the tracks can show the position of the digits and the fleshy outline, thus helping in the restoration of the foot. Also, they can show how an animal moved the limbs during locomotion. Such examples are shown in Figure 2. In (A) are shown a large tridactyl bipedal with footprint impressions with claw and pad preservation in digitigrade progression. The toe impressions match the formula: II, III, IV fitting to the pedal skeleton anatomy of the theropod Allosaurus. In (B) are shown the footprints matching those of Iguanodon, but there are also manus imprints present, showing slow movement.

Other observations show that there are manus imprints for both fast and slow-moving animals, indicating that Iguanodon was mostly a quadrupedal moving dinosaur [21].
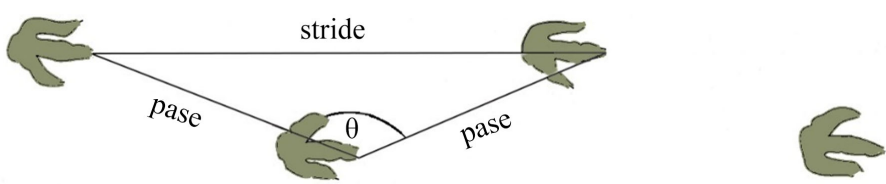

Figure 1. Footprints of a bipedal dinosaur and corresponding nomenclature. 


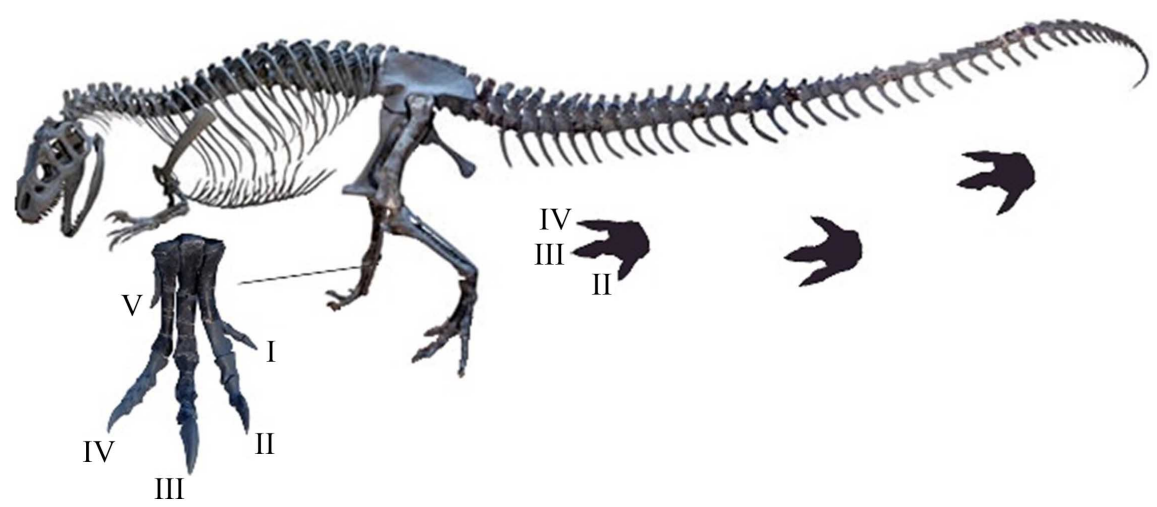

(A)

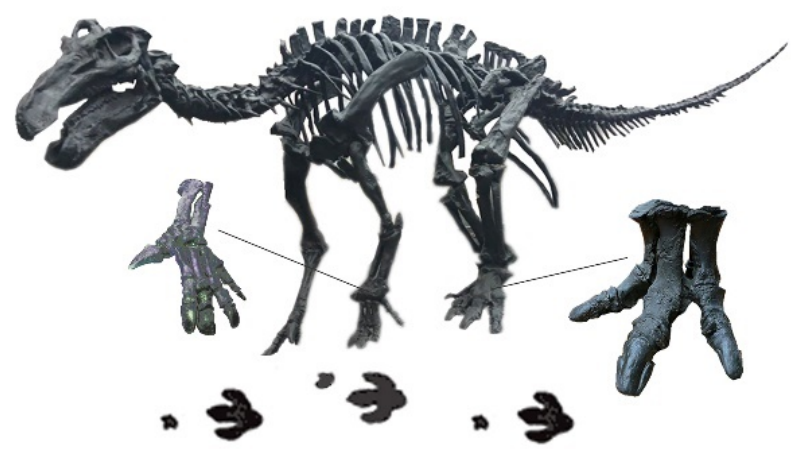

(B)

Figure 2. (A) Allosaurus footprint in digitigrade progression and digit identification. (B) Iguanodon manus imprints are found for fast and slow-moving animals, showing a primarily quadrupedally moving dinosaur.

\subsection{Evidence from Bones}

By examining the skeleton morphology and comparing it to living animals, the articulation of the limbs of dinosaurs and their movement can be suggested (Figure 3). For example, the knee joint of Tyrannosaurus rex is similar to those of birds. In this case the large inner condyle of the femur carries most of the load. At the same time a thin angular outer condyle moves in a groove between the tibia and the fibula, which stops the knee for turning about its long axis. Most post-thecodont archosaurs could not straighten their knees without dislocating the joint and therefore they had kept their knee in a flexed position. This is true even for large dinosaurs as Tyrannosaurus rex (Figure 4) - but also for Triceratops and Shantunggosaurus [22].

\subsection{Observation of Living Bipedal Animals}

By observing how a bird walks, one can reasonably suggest how a biped could move about since extant birds evolved from theropods. One must also have in mind that the avian skeletal design and function arose in major stages but for other purposes [23]. During dinosaur evolution differentiations in the hip, hindlimb and tail undeniably affected the way various species of dinosaurs walked 


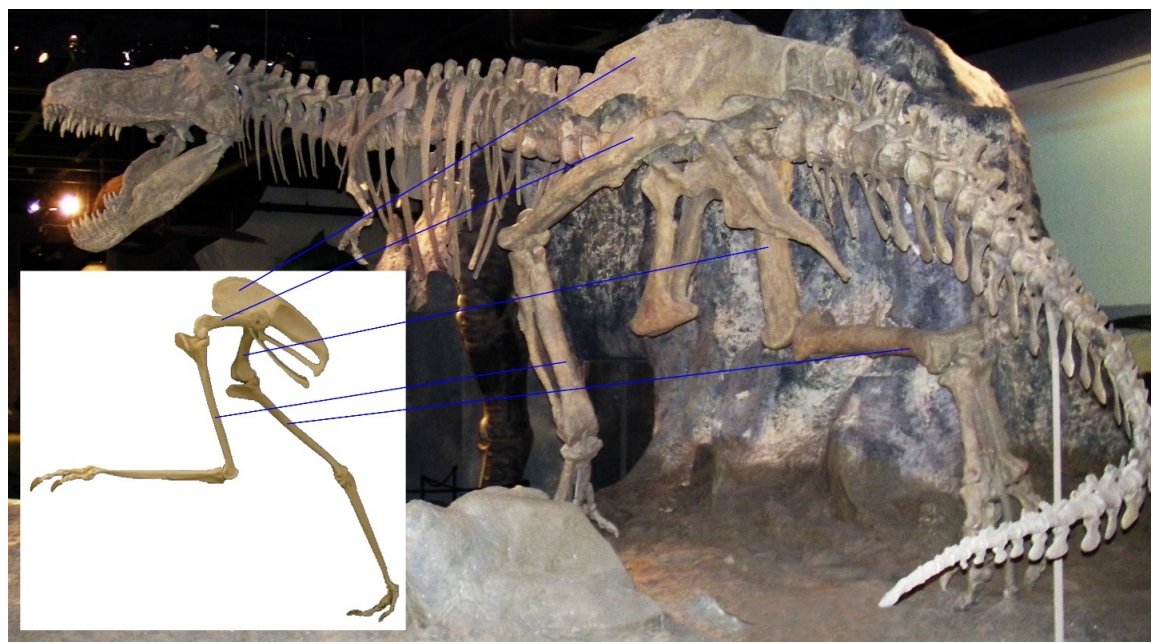

Figure 3. Articulation of the hind-limbs of Tyrannosaurus rex in comparison to the skeleton of a fast-moving emu.

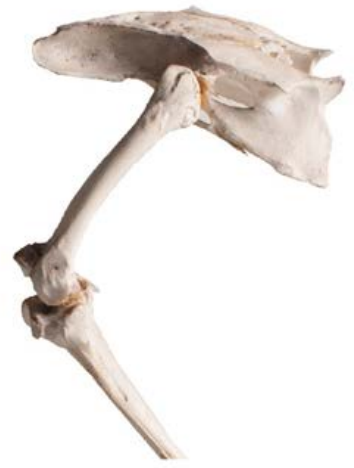

(A)

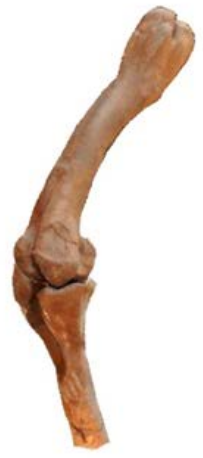

(B)

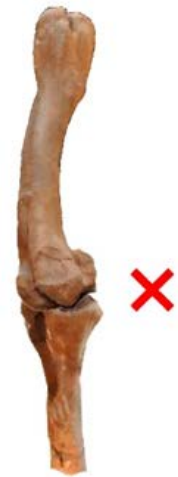

(C)

Figure 4. The knee joint of Tyrannosaurus rex is similar to those of birds and is articulated in a similar way. (A) articulation of the left knee of a chicken compared to the correct articulation of the hind-limb of Tyrannosaurus rex (B). (C) wrong way of articulating the knee of Tyrannosaurus rex.

and ran, but the locomotion of a bird is the closest living example. Scientists went as far as raising chicken wearing artificial tails, and thus transferring the center of mass more posteriorly, to study their movement [4]. The relevant results showed that the femur was held at a more vertical orientation during standing and femoral displacement during locomotion was increased. Therefore, to understand the general way bipedal dinosaurs walk about, extant birds should be observed. Figure 5(A) and Figure 5(B) describe such cases. When one foot touches firmly on the ground, the other is first raised up and moves to the front very quickly with the toes curling inward to one another and backward when the foot is raised. Then the foot stretches in order to offer a wider base and accept the weight when touching down. The front phalanges touch first on the ground and all the weight is transferred to the foot vertically downward. Then the cycle is repeated with the other foot. 

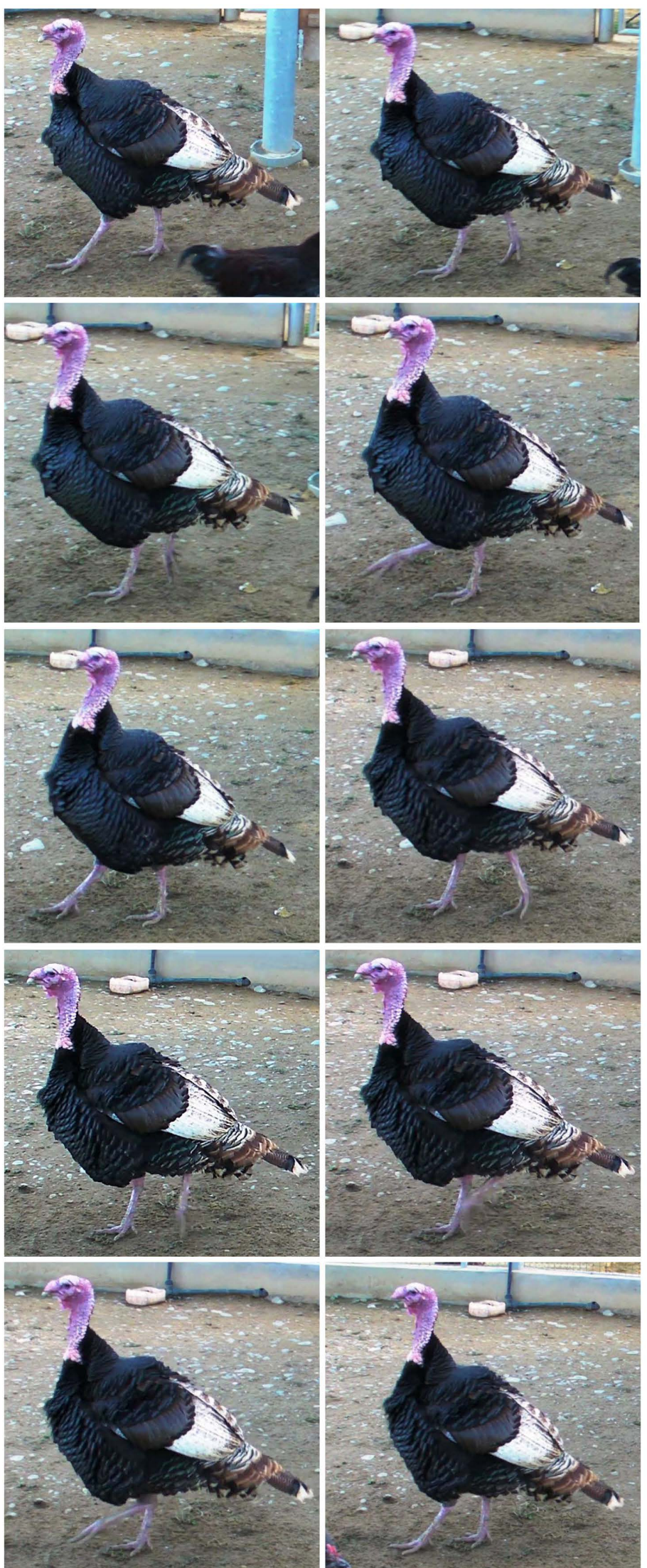

(A) 

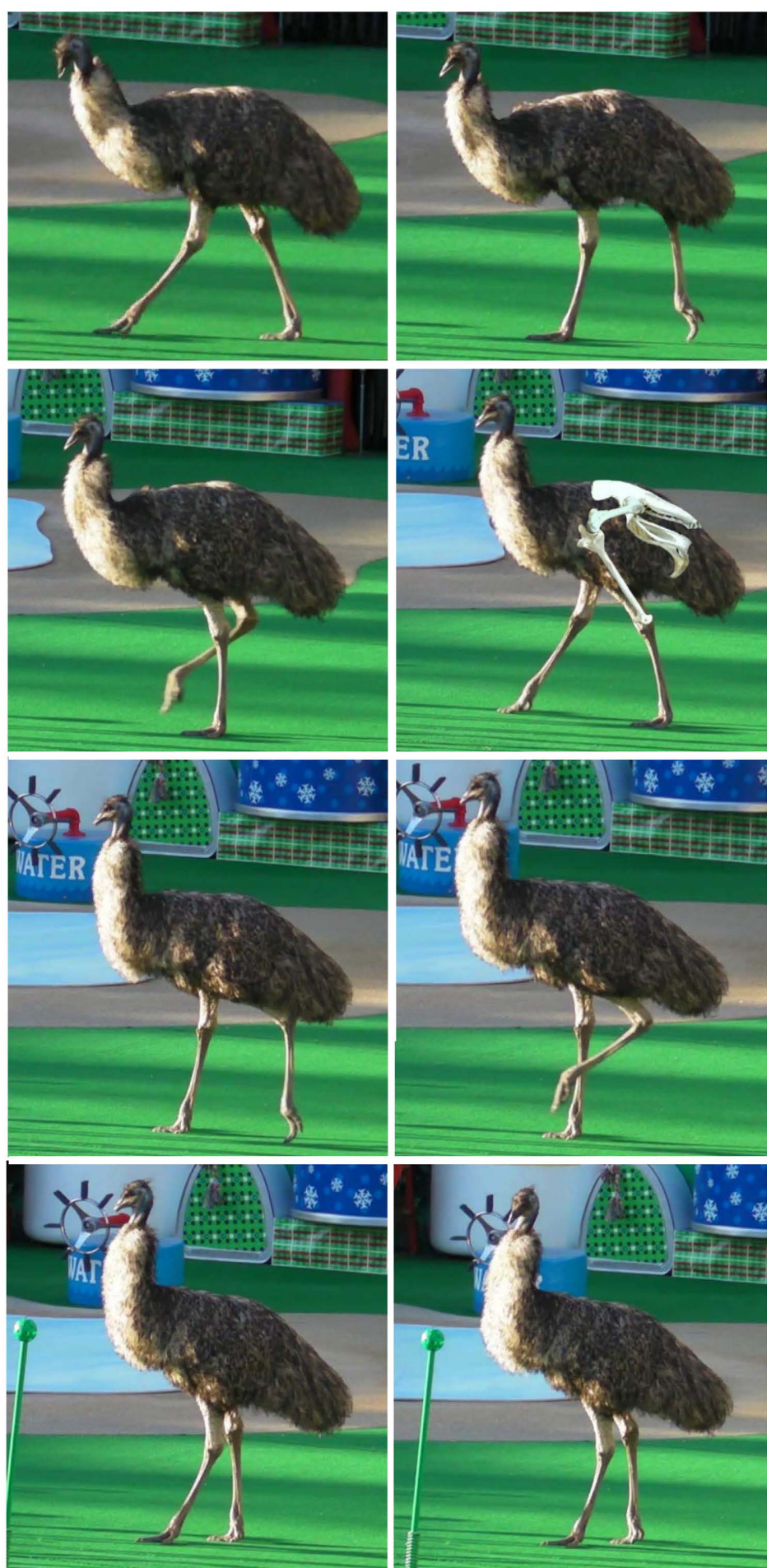

(B)

Figure 5. (A) A series of photographs showing a turkey walking about; (B) A series of photographs showing how an ostrich walks about. The third capture has part of the skeleton superimposed.

As explained above, with the exception of the more vertical orientation of the femur during standing and increased femoral displacement, biped dinosaurs are 
thought to be moving in a similar way as a bird. An excellent presentation was published by Lee et al. for Deinocheirus mirificus, which can be watched in a video sequence [24].

\section{Postures of Quadruped Dinosaurs during Walking}

\subsection{Evidence from Tracks}

Footprints can indicate the natural position of the claws during walking.

As an example, Figure 6 shows a reconstruction of the right pes of Apatosaurus with oblique orientation of the pedal claws compared to a relevant right pes print.

Also, series of tracks in various locations, of any specific dinosaur, can be found and studied. Such tracks are indicated in Figure 7, where the Sauropod manus orientation in trackways is shown [26]. The study of similar trackways by Bonnan [27] resulted in suggesting that sauropods had a semi-tubular manus. Their radius and ulna were relatively parallel to one another, augmenting the forelimb to lessen the shear stress during the support phase.

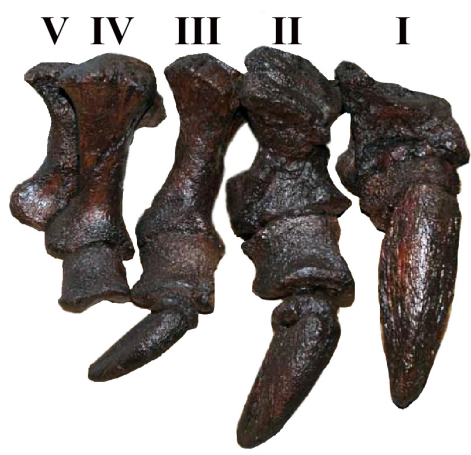

(A)

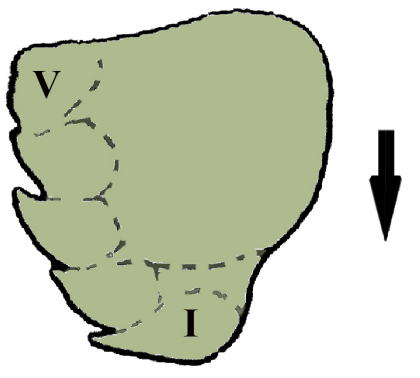

(B)

Figure 6. (A) Right pes of Apatosaurus with numbered digits; (B) right pes print of Brontopodus oriented relative to the midline of trackway (arrow), (see also study in [25]).

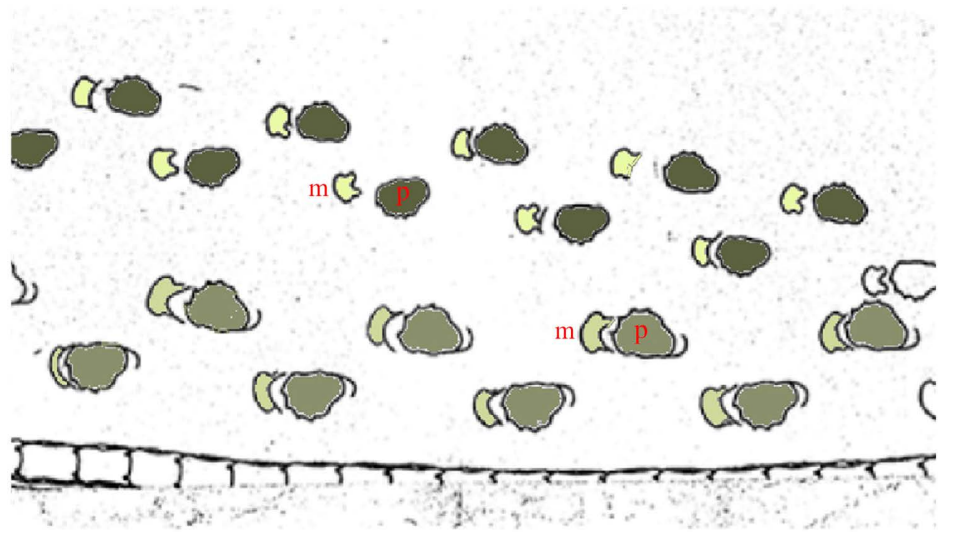

Figure 7. Sauropod manus orientation in the Paluxy River dinosaur tracksite that is one of the most famous in the world. Abbreviations: $\mathrm{m}$, manus; p, pes (modified from [26]). 
Sauropod trackways are of two different types: 1) "narrow-gauge", in which both manus and pes prints are very close to the trackway midline, and 2) "widegauge", in which the prints are far apart from the midline (Figure 8). Body size, morphology or behavior differences between the animals to which the tracks belong may account for this variation. Lockley et al. [28] suggest a mixed distribution of Jurassic track types followed by a decreasing of narrow-gauge tracks through time, with the latter almost completely absent from the Cretaceous, despite the availability of substantial sample. Wilson and Carrano [29] argue that gauge differences are due to skeletal morphology, and they suggest that titanosaurs were the makers of wide-gauge trackways. Figure 8 also shows two animals that could produce the wide and narrow trackways. In this case Opisthocoelicaudia, on the left, matches the wide-gauge trackway, while Supersaurus (a diplodocid), on the right, matches the narrow trackway. Both animals have the hind legs mostly vertical but gently sloping inward to match the tracks [30].

The tracks not only show relative speeds of the trackmaker, but also can reveal the size of the dinosaur. Some formulas correlating the different parts of the skeleton to the tracks are discussed in [31] and are used to derive the size of a titanosaur that fits the footprints of a specific trackway (Figure 9). Additionally (inset of Figure 9), individual prints of the ichnological record show the semitubular structure of the sauropod metacarpus.
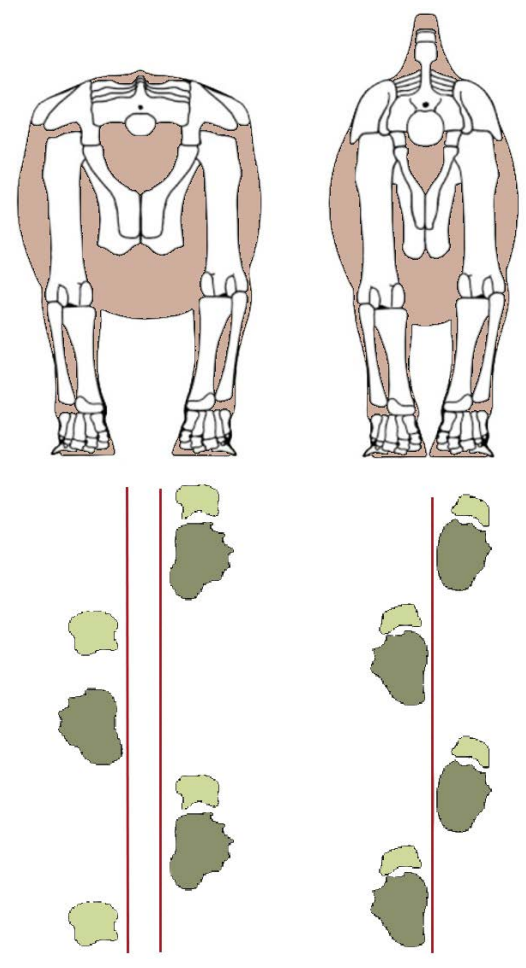

Figure 8. Opisthocoelicaudia (belonging to the clados $\mathrm{Ti}$ tanosauria), on the left matching the wide-gauge trackway and Supersaurus (a diplodocid), on the right, matching the narrow trackway both animals have the hind legs mostly vertical but gently sloping inward (modified from [30]). 


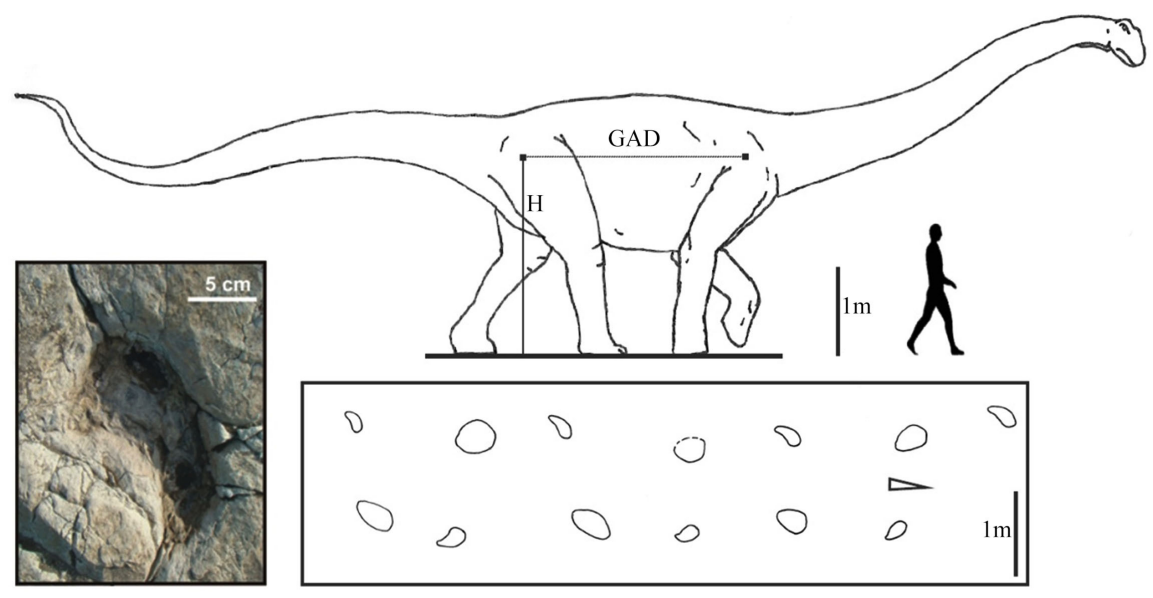

Figure 9. Sketch of a derived titanosaur in scale with the footprints of a trackway. Left, inset shows the left manus track of Titanopodus mendozensis. Abbreviations: GAD, gleno-acetabular distance; $\mathrm{H}$, height of hip joint (modified from [31]).

\subsection{Evidence from Bones}

Analysis of footprints of sauropods and manipulation of specimens have shown that sauropod dinosaurs have unguals that are notable for their unusual shape and orientation (Figure 10) and are different from those of mammals that they are often compared with. Sauropod manual unguals, early in their evolution, underwent severe reduction, as they were lost on all digits except digit (D)-I. The pedal unguals, on the other hand, became hypertrophied and laterally compressed with an unusual, angled orientation [32].

Additional information on pes and manus reconstruction is given by [33]. Also shown in Figure 10, are the predicted sauropod pes and manus tracks based on skeletal morphology. Studying the osteology of quadrupeds and comparing it with living animals the paleontologists can restore the bones in their correct form. As an example, in sauropods and stegosaurus the bones allow a rectigrade posture of the hind limb (Figure 11) in contrast to other dinosaurs who have a very bird-like knees [22].

\subsection{Observation of Living Quadruped Animals}

Although elephants have osteological and mass differences with dinosaurs, and especially they lack a huge tail, observing the largest land animal walking and moving about, will give a general idea on how to reconstruct a sauropod. Sequences of photographs of a walking elephant are shown in Figure 12 and Figure 13. In these figures the following walking steps are observed:

1) The left front foot touches the ground and the right hind leg is raised up

2) The right hind leg is moved forward and the right front is raised up

3) The right hind leg touches the ground and the right front is moved forward

4) The right front foot touches the ground and the left hind leg is raised up

5) The left hind leg is moved forward and the left front is raised up

6) The left hind leg touches the ground and the left front is moved forward 


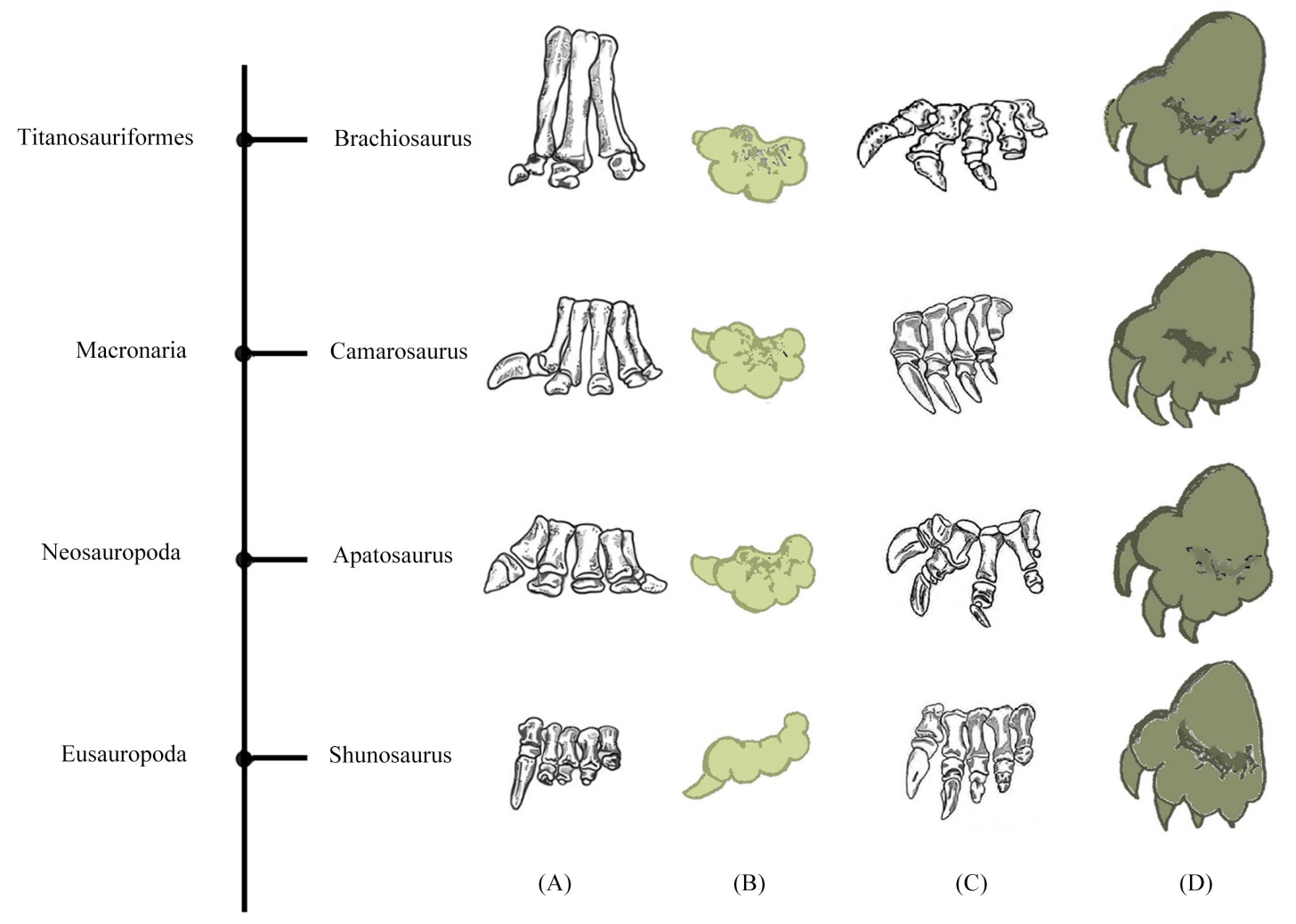

Figure 10. Evolution of: (A) sauropod manual phalanges (left manus); (B) predicted tracks of sauropod manus; (C) sauropod pedal phalanges (left pes); (D) predicted tracks of sauropod pes. During evolution a reduction and loss in the manual phalanges is observed. Pedal phalanges are also reduced during evolution but unguals become enlarged, especially on D-I and D-II. Relative positions of manus-pes pairs are not shown (not to scale). For more details see [32] and [33]).

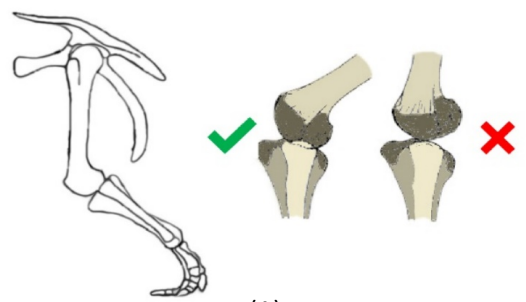

(A)

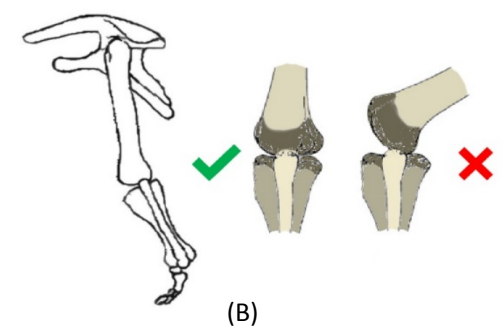

Figure 11. (A) The articulation of the left knee of Triceratops horridus, where the knee is flexed with the outer femoral condyle running in the groove made by the fibula and tibia, and (B) Stegosaurus stenops, where the knee is straightened, which works only in Stegosaurus in which the fibula is proximally extended and continues to brace the outer femoral condyle (see also [22]). 

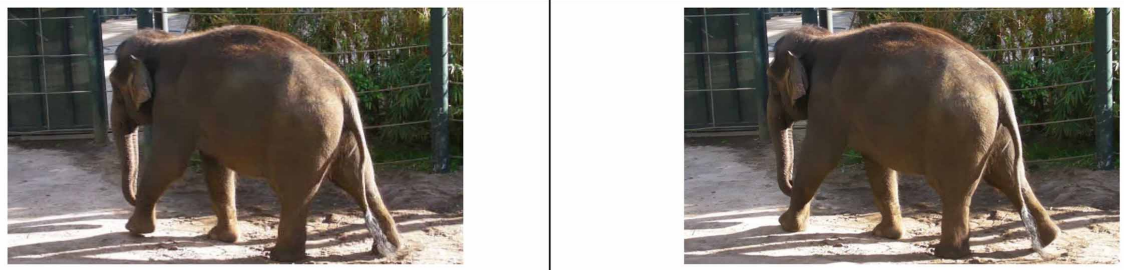

1. the left front foot touches the ground and 2 . the left front foot touches the ground firmly the right hind leg is raised up

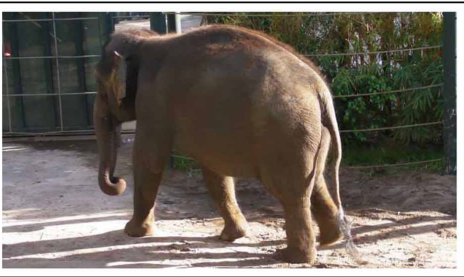

and the right hind leg is raised up further

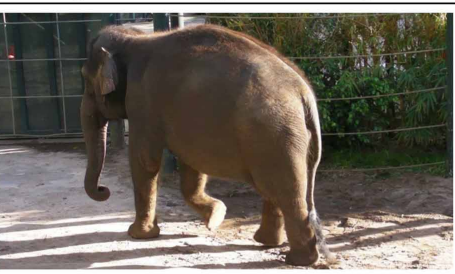

3. the right hind leg is moved forward and 4 . the right hind leg is further moved forward the right front is raised up and the right front is raised up further
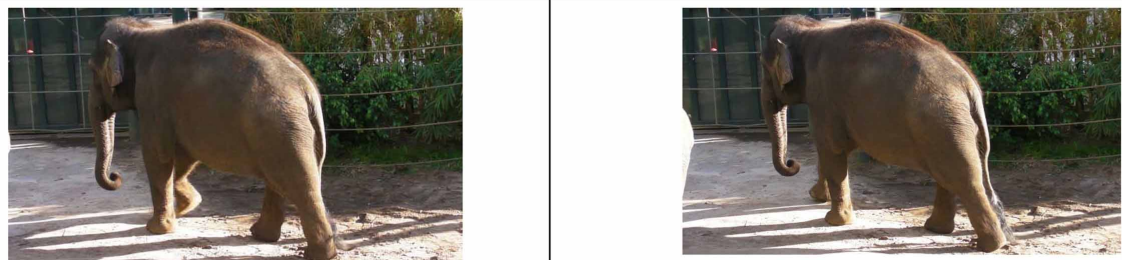

5. the right hind leg touches the ground and 6 . the right hind leg touches the ground firmly the right front is moved forward and the right front is moved forward further
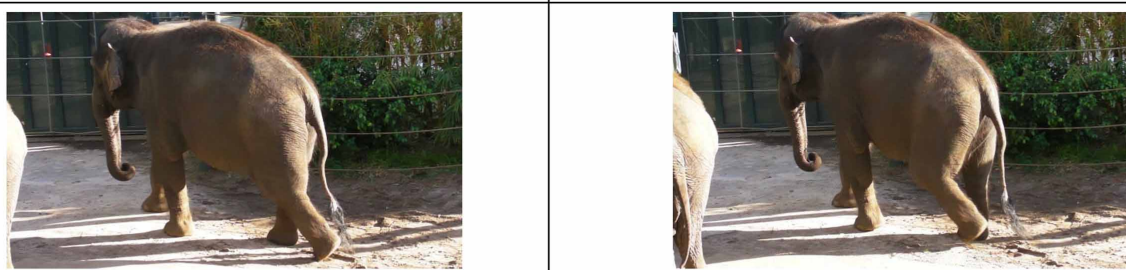

7. the right front foot touches the ground 8 . The left hind leg moving in front and the left hind leg is raised up
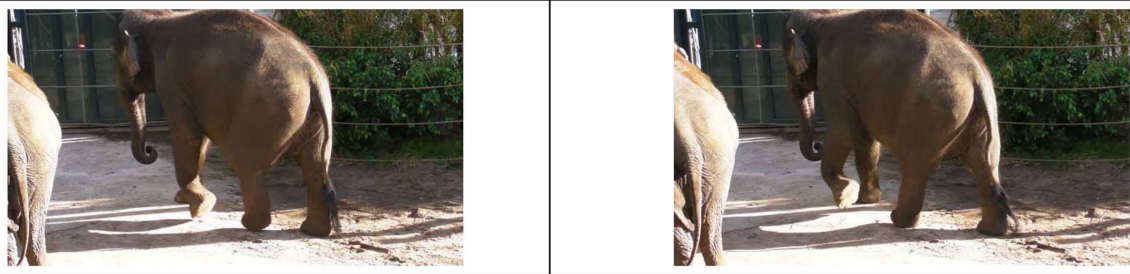

9. the left hind leg is moved forward and the 10 . the left hind leg is further moved forward and left front is raised up

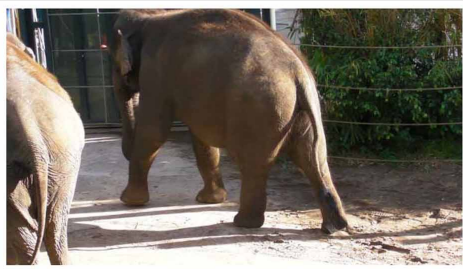
the left front is raised up more

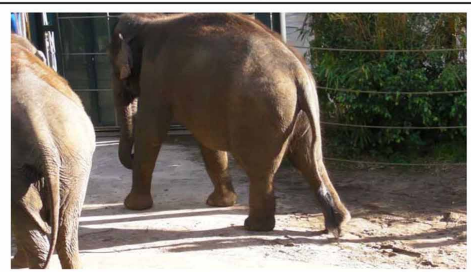

11. the left hind leg touches the ground and the left front is moved forward

12. the right hind leg is moved forward and the right front is raised up

Figure 12. Walking sequence of an elephant seen from the rear. 


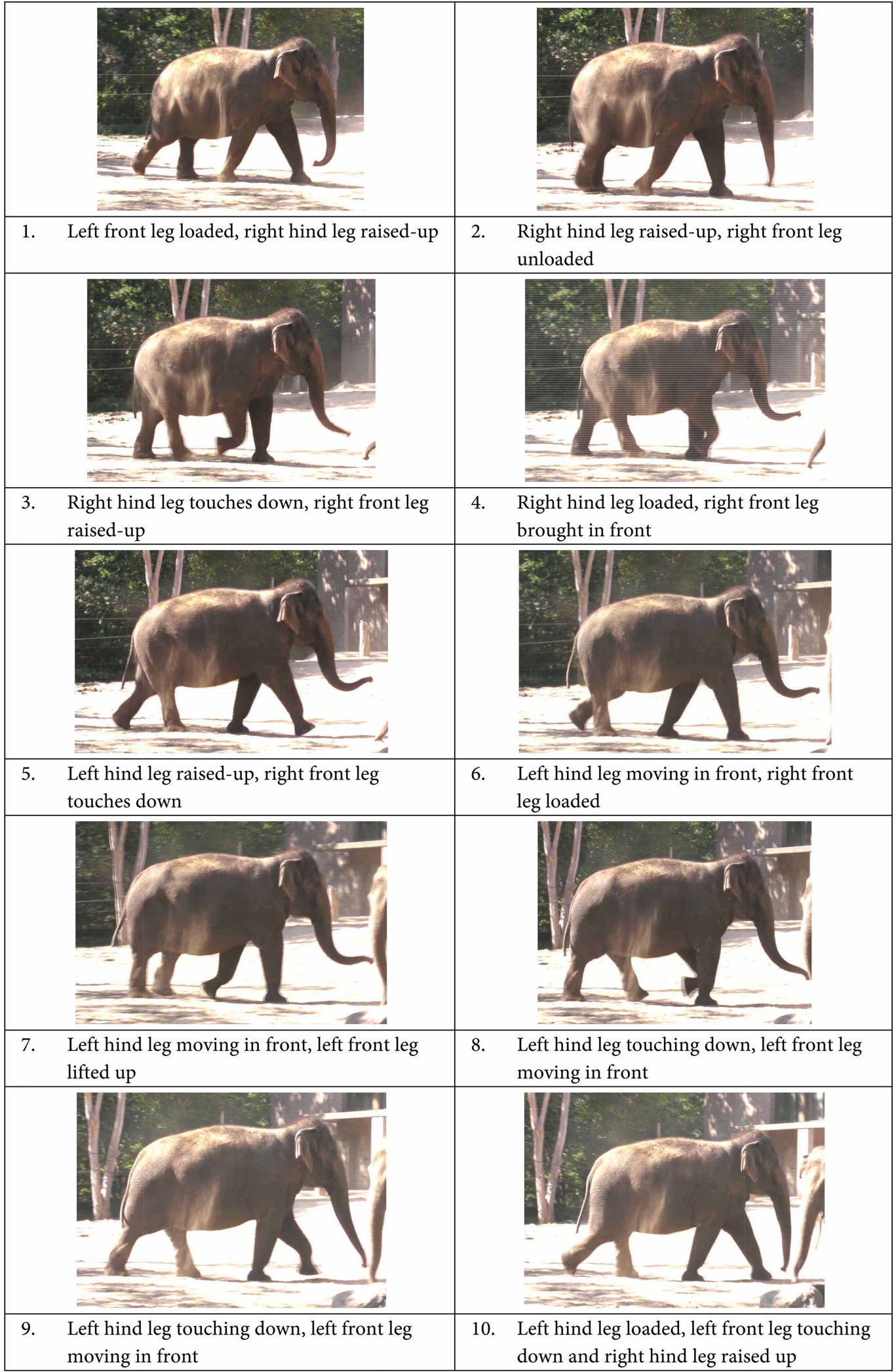

Figure 13. Walking sequence of an elephant seen from the side. Observe that there are instances, like in (1) and (10), that if seen isolated from the sequence, the animal gives the impression that moves both right site legs in one direction and simultaneously the left in the opposite direction. 
Seen from the rear, the elephant can be considered as a "narrow-gauge" tracking animal with its vertical limbs generally angled inward, toward the midline, when walking or running. Of course, when it stands still it can keep its feet at any distance, as shown in Figure 14.

In a recent study Sellers et al. [34] generated a musculoskeletal model that used data captured by laser scanning a mounted skeleton and assigned muscle properties according to comparative data from living animals. The model was used to demonstrate how one of the largest sauropods, Argentinosaurus huinculensis, which was 40 -meters long and weighed 83 tons, may have moved. With the learning techniques of the machine that minimizes metabolic cost, a simulation demonstrating the possible movements was generated. A sequence of the simulation can be found in [34].

\subsection{Feeding Style}

In restoring a quadruped one can also choose a feeding position. Some dinosaurs, like Barosaurus, Diplodocus, Brontosaurus and Stegosaurus could rear up and feed tripodally. Figure 15 presents the feeding styles of some of the North American dinosaurs [35].
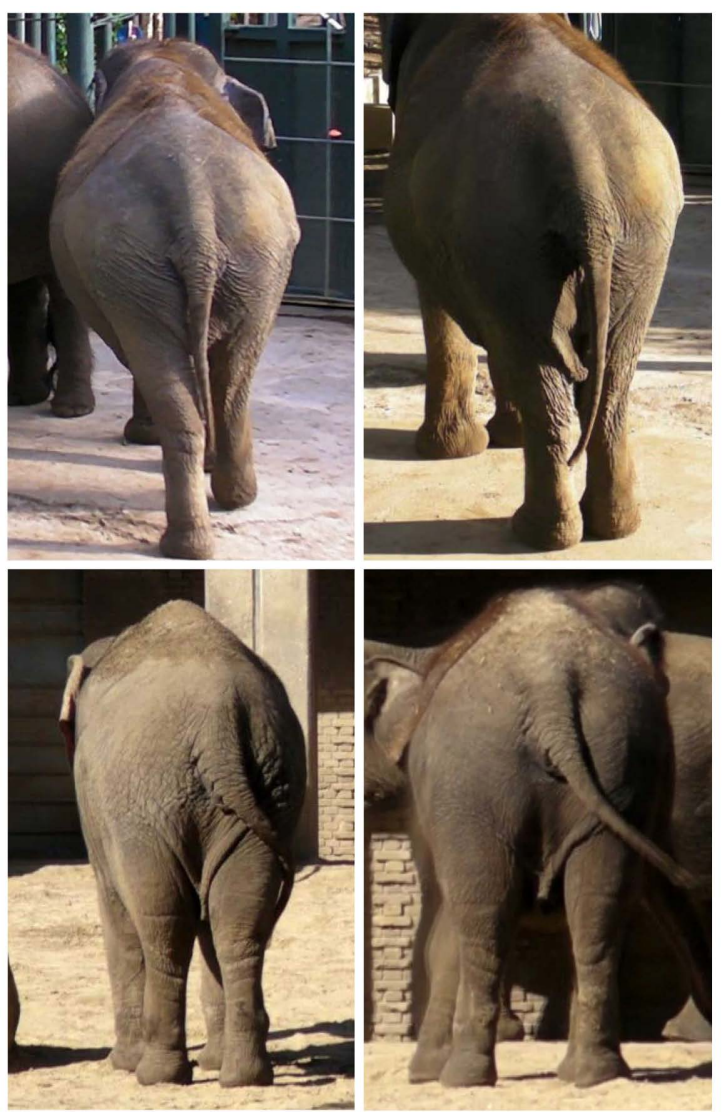

Figure 14. The elephant in the first image is walking keeping its limbs angled inward, toward the midline. When standing still, as shown in the remaining images, it keeps its feet in different distances. 
LATE CRETACEOUS-UTAH
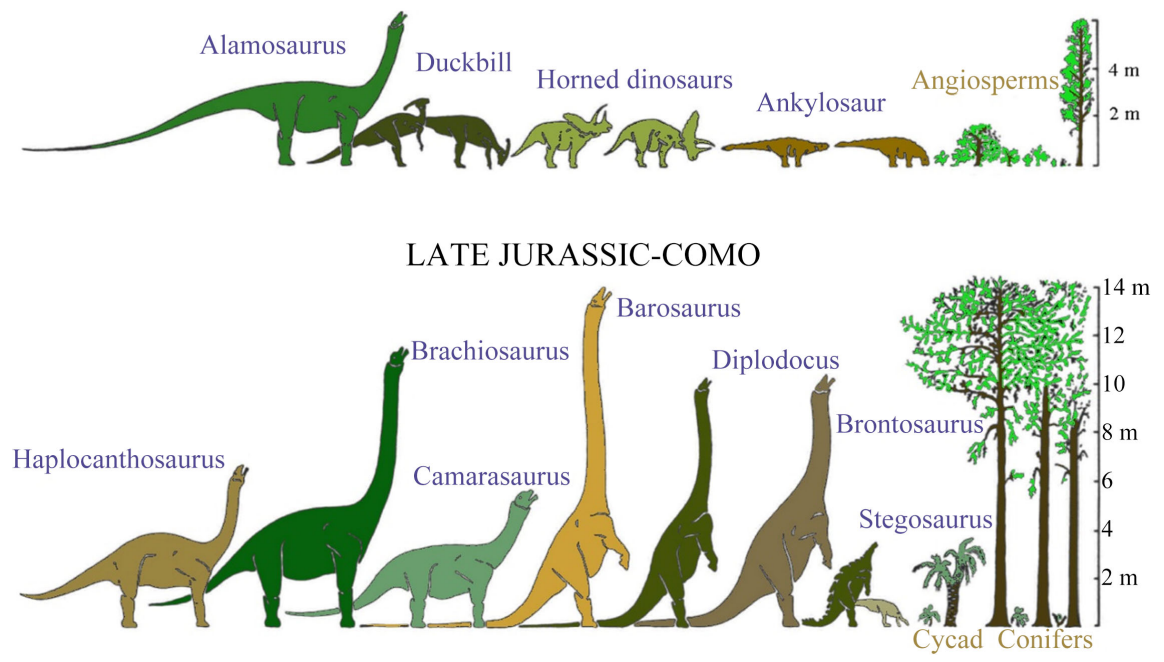

Figure 15. Dinosaur feeding style. At Como in the Late Jurassic, the Stegosaur and Barosaurus, Diplodocus, and Brontosaurus could rear up and feed tripodally. In Late Cretaceous habitats in Utah low-feeding beaked dinosaurs dominated the plant-eating role (modified from [35].

Some plant-eating dinosaurs like Brontosaurus and Stegosaurus that were designed for rearing up on hind legs and tail, had tall vertebral spines above the hips, so that the back muscles and ligaments had strong leverage for raising the body. Other big herbivores had shorter vertebral spines and most probably had stayed on all fours [35]. An articulated skeleton of Brontosaurus in tripodal position in shown in Figure 16 [36].

\section{Sauropod Long Necks and Heads}

Because of their weird appearance with enormous bodies, elongated tales and necks and relatively tiny heads, sauropods pose fascinating questions concerning their appearance, feeding habits and especially movements.

The position of the long necks held by sauropods induced much controversy and there is no agreement between scientists. Because of the neck length a number of researchers assume that large sauropods were unlikely to have carried their necks erect and they assume that the necks were held nearly straight and horizontal and because of the high blood pressure needed, is also assumed that in a number of cases the neck could not be raised much above shoulder level [37].

According to Stevens and Parrish [38], the neutral pose of the cervical vertebral column, corresponds to a rest state at each joint along the column. They observe consistency between the pose habitually held by extant vertebrates and the geometrically-defined neutral posture. Thus, the neutral pose is revealed by 1) the sigmoid curvature feature of avian and equine necks, 2) the catenary shape of the camel's neck, 3) the sharp upturn at the base of the giraffe neck. Referring to the giraffe neck in particular, they observe that its neck is sharply angled at its 


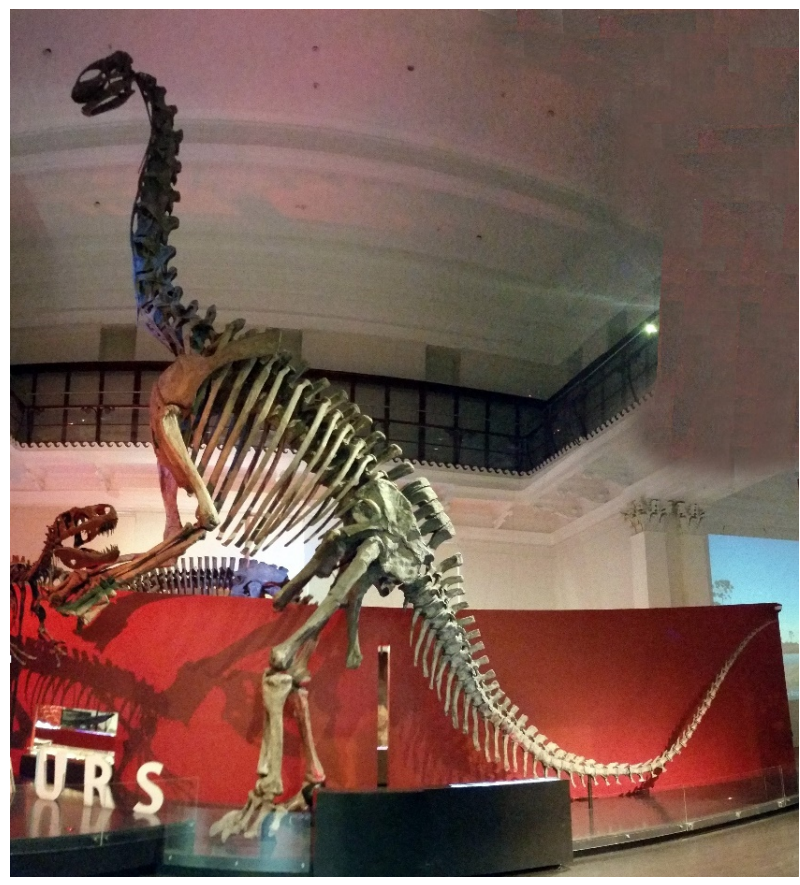

Figure 16. The giant plant-eating sauropod dinosaur Jobaria tiguidensis from Africa, skeleton in tripodal position [36].

base while held in the undeflected neutral position and that this angulation arises from keystone-shaped (wedge-shaped) vertebrae, and not from deflection at the intervertebral joints. They assert that, with no known exception, the curvature characteristic of the axial skeleton of a given vertebrate arises in the undeflected state, and not from chronic flexion out of the neutral position, reflecting the morphology of the vertebrae.

The alignment of the zygapophyses and the nulling of the deflection at the central articulation geometrically define the neutral state of deflection between successive vertebrae. The pre- and post-zygapophyses, if present, are generally centered within their range of dorsoventral travel when the two vertebrae are in the undeflected state (Figure 17). Articulation of axial elements in sauropods allows inference of their neutral or undeflected state to be made with some confidence.

With the neutral pose established, a biomechanical analysis of the motion range within the neck will give some indication of the feeding height of the animal. Therefore, in order to introduce a scientifically testable method, and not sheer speculation, computer modeling is used together with osteological observation. Stevens and Parrish [38] conclude that cranial morphology, gross tooth shape and dental microwear indicate that the narrow-toothed sauropods (i.e., diplodocids, nemegtosaurs, at least some titanosaurs and euhelopodids) mainly cropped relatively soft vegetation and/or strained planktonic plants and animals, in order to be fed. The broad toothed forms (i.e., Camarasaurus, Brachiosaurus, potentially vulcanodontids and cetiosaurs) were seemingly fed by more durable plant material that included cycads and possibly conifers. Reconstructions of the neutral position of the vertebral columns for six well-known Jurassic and Creta- 
ceous sauropods (namely, Apatosaurus, Brachiosaurus, Camarasaurus, Dicraeosaurus, Diplodocus and Euhelopus) indicate that these taxa had necks inclined slightly downward in the undeflected position. The reconstruction of Apatosaurus louisae and Brachiosaurus brancai, which shows osteologically-determined neutral pose to pre-sacral axial skeleton and allowable movement, is shown in Figure 18.

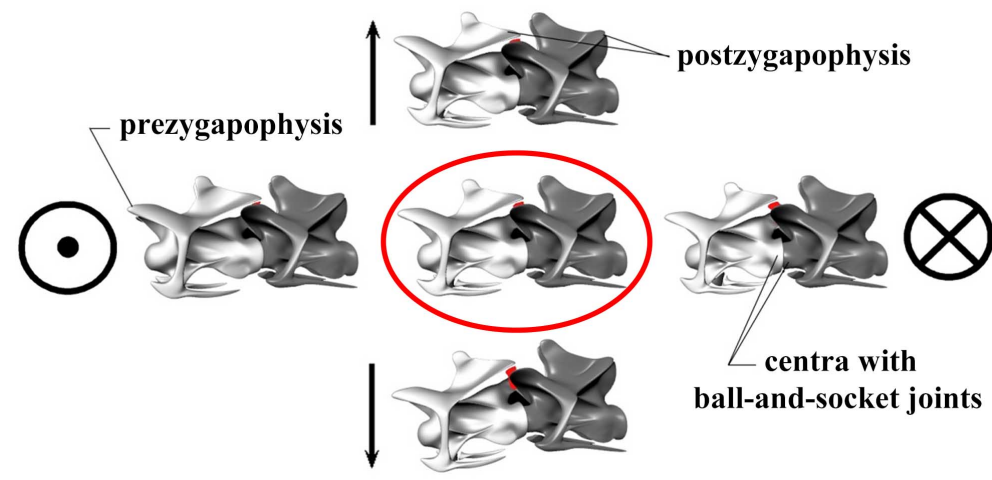

Figure 17. Articulation between two successive vertebrae. Middle, in red oval: undeflected or neutral state, Peripheral images: maximum allowable movement in the indicated direction without disarticulation (modified from supporting material in [10].

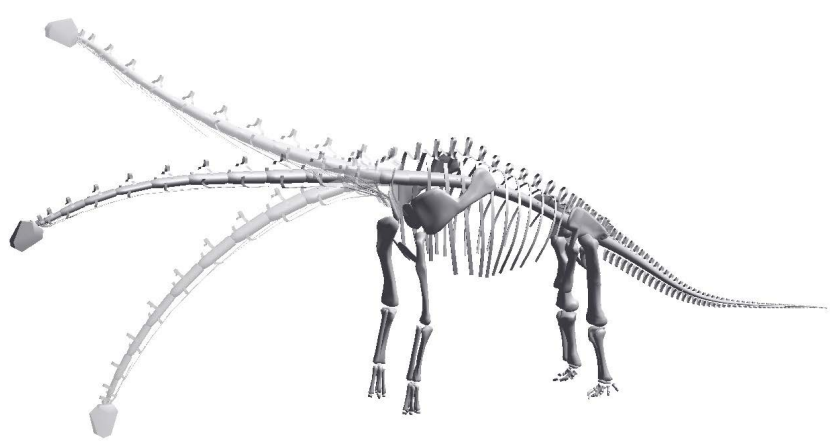

(A)

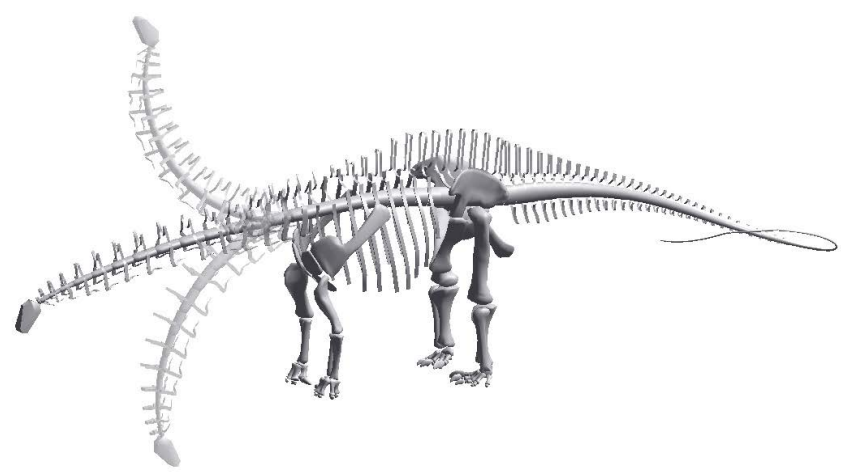

(B)

Figure 18. Brachiosaurus brancai (A) and Apatosaurus louisae (B), showing osteologically-determined neutral pose to pre-sacral axial skeleton and allowable movements [38]. 
Stevens [10], based on vertebral osteology, interpretations of missing soft tissues, intervertebral flexibility issues, examined sauropod neck flexibility and found that, in osteologicall terms, articular surfaces limit the reconstruction movements of the cervical vertebral column as additionally do soft tissues. According to his findings, the sauropod cervico-dorsal vertebral column is basically straight, as opposed to the curvature displayed in the extant vertebrates naturally holding their heads above necks kept rised. Sauropod necks, could sweep out large feeding surfaces, but were not as capable to explore the enclosed volume by retracting their head in an avian manner (see Figures 19-21).

Paul [39] believes that the short-necked diplodocoids held their necks nearly straight and horizontal, but for other groups many straightly restored sauropod necks exhibit clear misarticulations or are based on vertebrae that are too distorted and incomplete to be reliably articulated.

Contrary to the belief of Stevens above [10], because very rarely are sauropod cervicals preserved complete and undistorted, due to their size and fragility, Taylor et al. [13] believe that any analysis of the neck bones is subjective, depending on interpretations and assumptions. Also, the thickness of the articular cartilage between the centrums of adjacent vertebrae affects posture. The cartilage extends (raises) the neck by an amount almost proportional to the thickness of the cartilage [40] and gives it extra amount of flexibility (Figure 21).

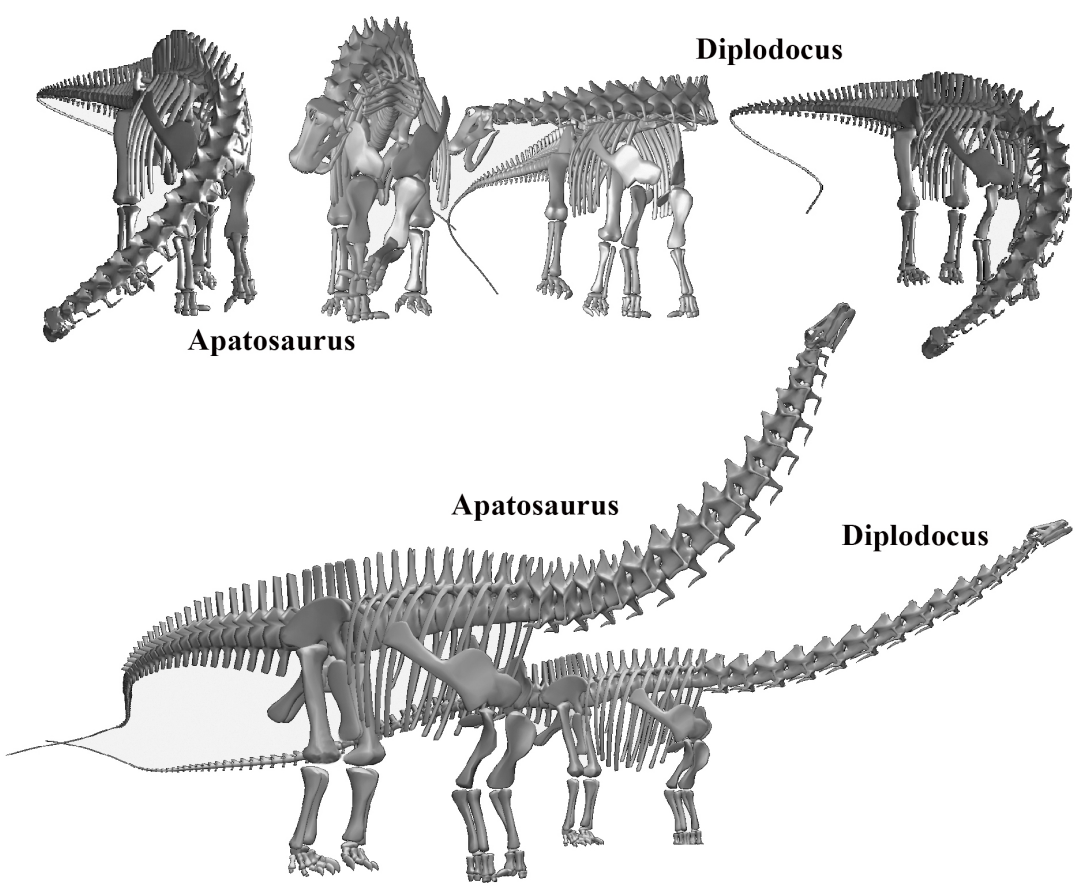

Figure 19. Diplodocids' relative inflexibility did not prevent them from sweeping out a large feeding surface. Apatosaurus and Diplodocus are shown in various allowed movements. In extreme lateroventral flexion they could reach down and laterally to ground level; they are also shown in extremes of dorsal flexion. Diplodocus's vertebral joints at the base of the neck did not permit unlimited flexion, although the neck could sweep huge surfaces. Apatosaurus could reach higher despite having a somewhat shorter neck than Diplodocus (modified from [10]). 


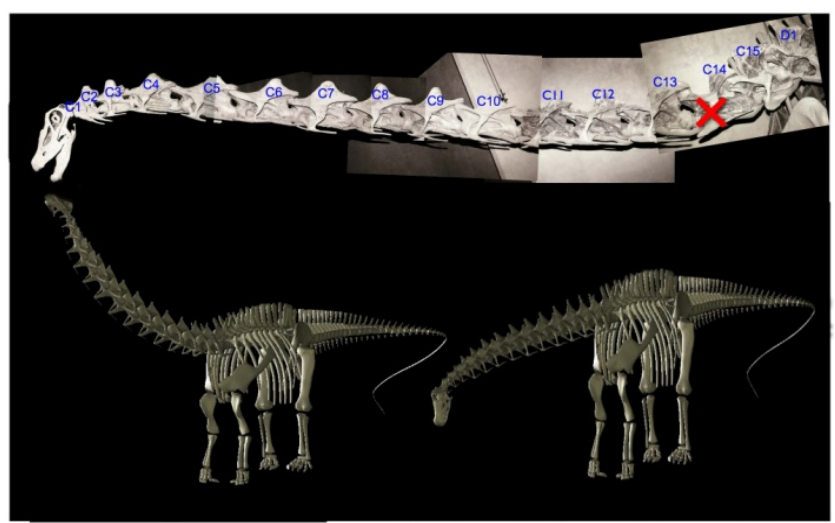

(I)

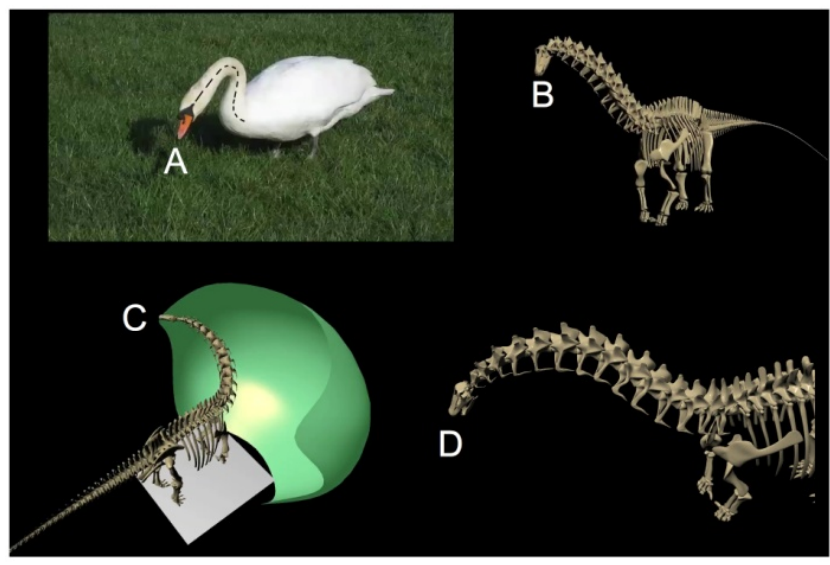

(II)

Figure 20. (I) The mount of Diplodocus longus exhibited in the Denver Museum of Nature and Science shows a sharp upward bend, which seems unnatural as the vertebrae in the vicinity of C13 - C15 look undeflected. The vertebrae should emerge straight from the shoulders as the simulations show. (II) Sauropod necks, at some instances, were expected to maneuver similarly to a swan (A). Apatosaurus could feed at any point across a huge feeding surface $(C)$, but the neck could not retract the head back toward the body (B, D) (modified from [10]).

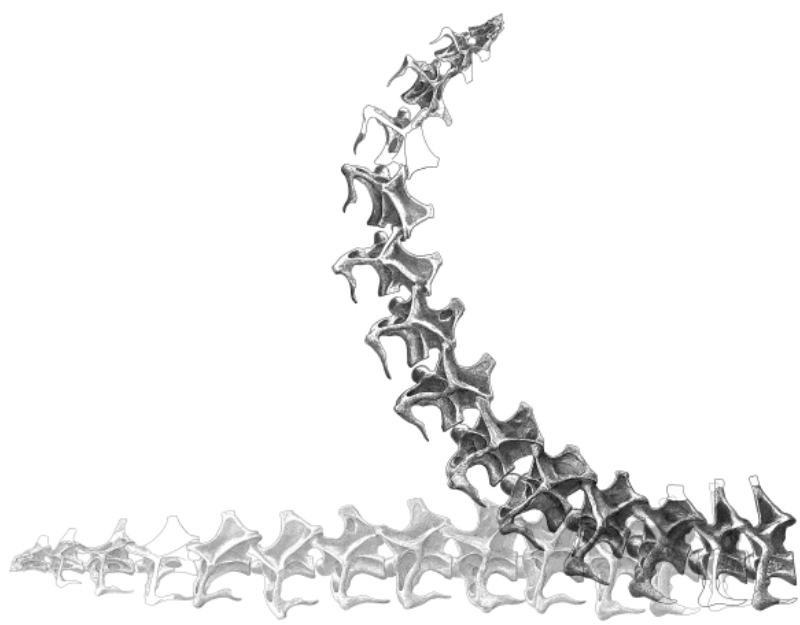

(A) 


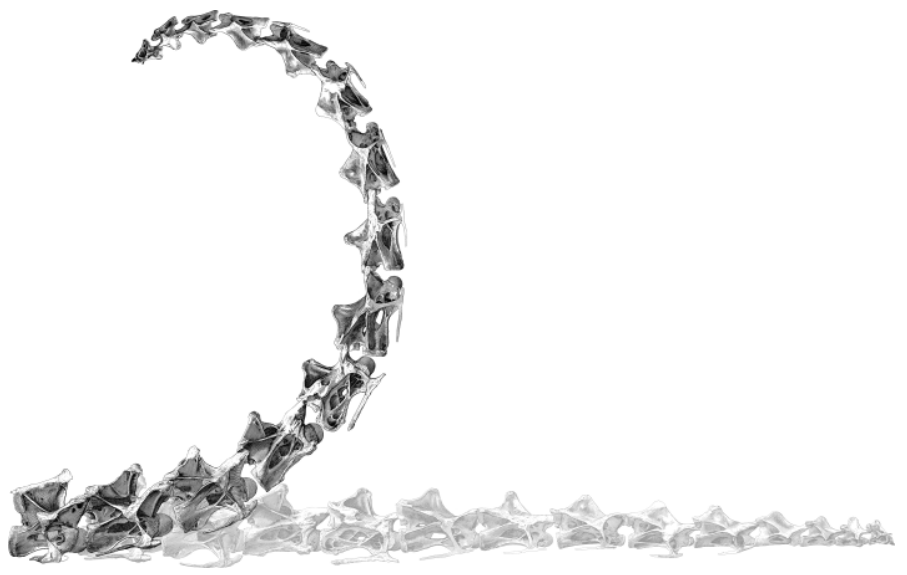

(B)

Figure 21. Although the habitual posture in life would not have been the illustrated one, adding cartilage to the neutral pose of the neck of (A) Apatosaurus louisae CM3018 and (B) Diplodocus carnegii CM84, would increase the flexibility. At the bottom, the vertebrae are composed in a horizontal posture [40].

It should be noted that the only example of preserved cartilage between the vertebrae in a sauropod neck is in two neck-base vertebrae of an old camarasaur that fused together before death. Contrary to the prediction of horizontal necked sauropods, the vertebrae are flexed upward as if the neck was held above shoulder level [39].

Therefore, for the moment there are various assumptions on which the posture of the neck is based, but none is conclusive because of the unknown factors existing for each one of them.

The same difficulty exists also for determining the position of the head, since this is connected to the neck position. As seen above, Stevens [10] concluded that sauropods did not have a sigmoid curve to the neck and were well-suited for directing the head to different locations on a "feeding envelope" surface and not at any point within the volume within that surface; i.e. they were feeding like a cow and not like a swan. According to Stevens's conclusions, sauropods had rather "stiff" necks, which more or less determined the head position as well (Figure 22). As a support to the position he places the head, Stevens presents a comparison of the location of the lateral semicircular canal (LSC) of the sauropod necks in sub-horizontal position, to that of 32 species of alert birds, showing consistency.

It should be noted that the semicircular canals are part of the inner ear and work as a type of motion sensors so that the brain keeps the body balanced, regardless of the posture. There are three semicircular canals, the horizontal, the posterior, and the superior, each providing a separate sense of directional balance.

Contrary to the above, Taylor et al. [13] present their own possible range, based again on the evidence of the semi-circular canal, using the range of habitual orientations found for birds. They believe that sauropods behaved in the 
same way as all extant amniote (mammals, turtles, squamates, crocodilians and birds) and they must have habitually held their necks extended maximally and their heads flexed maximally, so that the mid-cervical region was near vertical. As they stress, extant animals show wide variation in inclination of the "horizontal" semi-circular canal, which means that the orientation of this structure is not tightly constrained and can only give a general idea of the life posture of extinct animals' heads (Figure 23).

In another study, Marugán-Lobón et al. [41] suggest that, based on the available data in living birds (extant saurischian dinosaurs), the orientation of the LSC in non-avian saurischian dinosaurs could have been very variable and taxon-specific. In that case, using the LSC as a reference system for comparison, would lead to improper visual perceptions of craniofacial organizations, yielding significant descriptive inconsistencies among taxa. Enriching the data with other

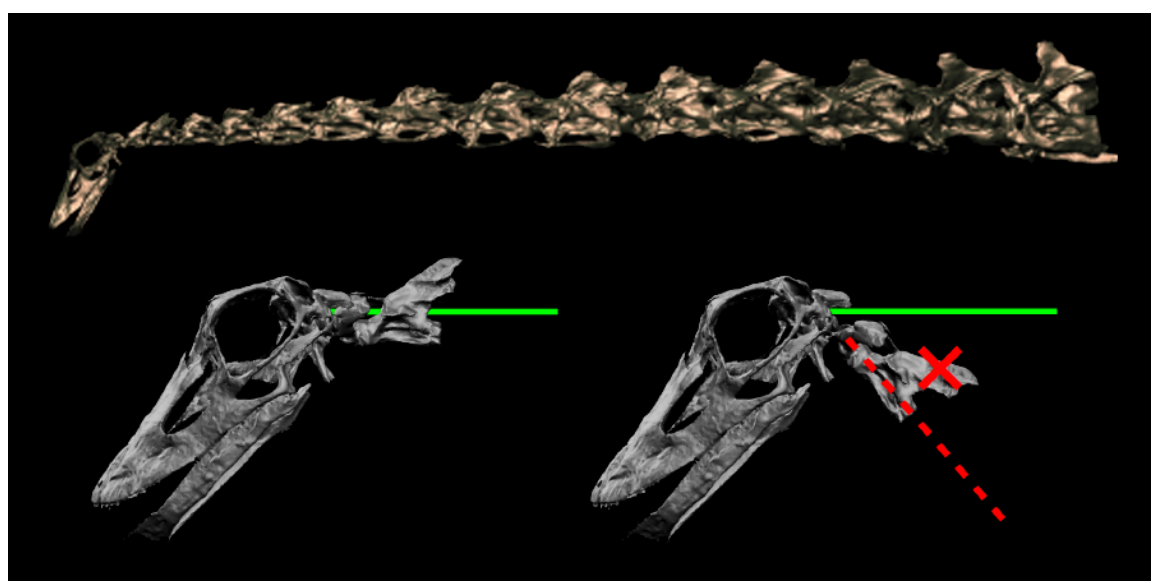

Figure 22. Digital reconstruction of sauropod neck and position of head (modified from [10]).

(B)

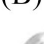

(A)

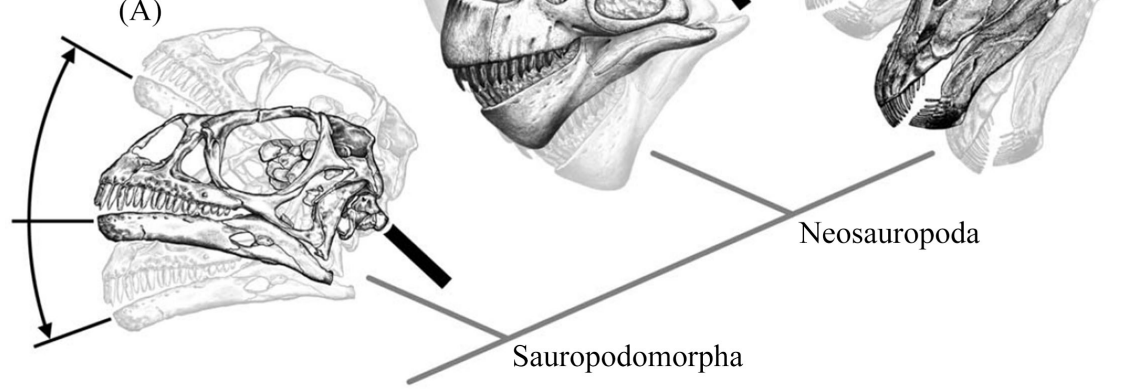

Figure 23. The heads of sauropodomorph Massospondylus (A) and the sauropods Camarasaurus (B) and Diplodocus (C), with HSCC (horizontal semi-circular canal) held horizontally, shown in habitual head angles (tilted $30^{\circ}$ upward and $20^{\circ}$ downward), which are similar to the range of habitual orientations found for birds. Black bars show the angles of the necks in neutral position relative to the heads [13]. 
morphologicaly homologous data does not improve the accuracy of the head position prediction. The final conclusion is that the lateral semicircular canal is not a consistent baseline for comparative studies on dinosaurs' craniofacial morphology.

Finally, Preuschoft and Klein [42] investigated sauropod neck posture and morphology in several clades from a mechanical viewpoint. They analyzed ways of sustaining loads and bending moments as well as torsion. Their findings are summarized in Figure 24, where views from above on sauropods show that the moment of the bulky neck is so large that, when moved left and right in large extent, using the inner foot is necessary in order to prevent imbalance of the whole body. To avoid imbalance, the tails are also needed to flex in opposite directions from the neck.

\section{Dinosaur Tails}

One important question is how dinosaurs held their tails. A review of tail tracks shows that they are rare, indicating that dinosaurs usually held their tails above ground; still, at least 38 records of dinosaur tail traces exist in the literature [43]. The tail impressions are either resting traces or tail drag impressions for locomotion traces. Estimated speeds of tail trace makers seem to be quite low. The abundance of tail traces of bipedal, and not quadrupedal, dinosaurs is considered to reflect behavior.

In bipedal dinosaurs, the long tail was acting as a counterbalance to the head and body that were held horizontal, with the femur sloping strongly forward to place the feet below the center of gravity that was ahead of the hip socket [39].
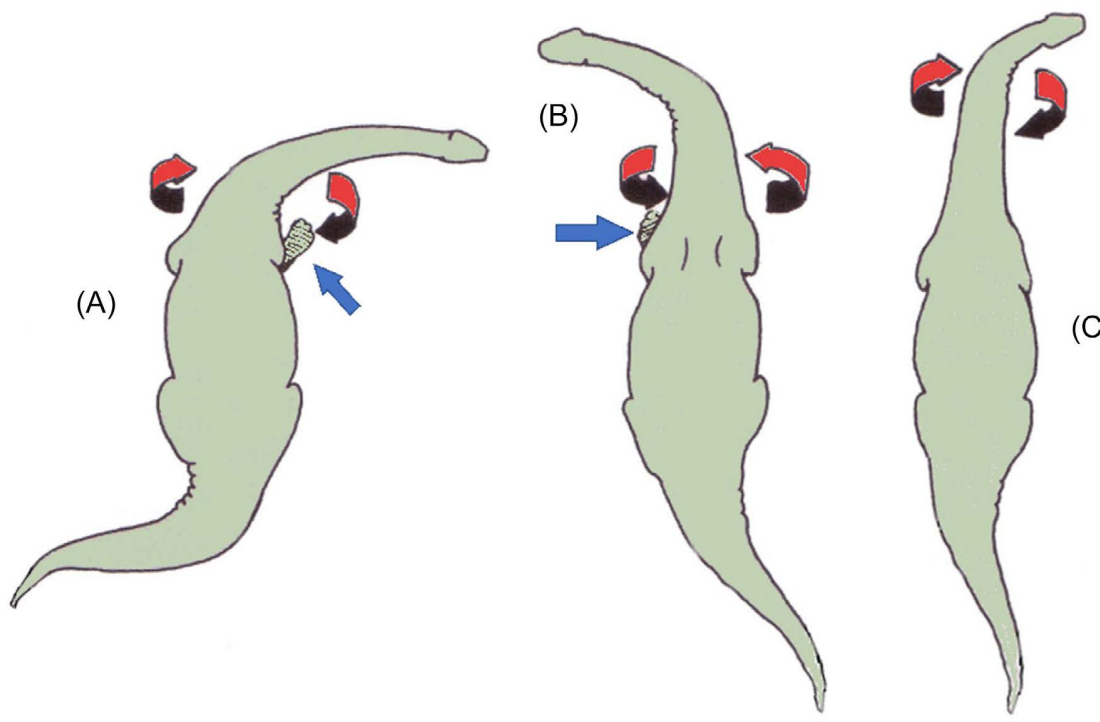

Figure 24. View from above (top) on sauropods, flexing their necks laterally. (A) The moment of the bulky neck is so large that the inner (right) foot is placed laterally to prevent imbalance of the whole animal. (B) Similar to (A) for flexion of the neck to the left. (C) No movement of the feet is necessary for small rotating movement. In all cases, the tails are flexed into the direction opposite to the neck to reduce the imbalance caused by lateral flexion of the neck (modified from [42]). 
In the case of sauropods, there does not seem to exist a realistic idea of what the animals did with their tails, except keeping them horizontally to act as a counterweight for the neck [42]. Osteological evidence of both origin and insertion indicates that a substantial caudofemoralis longus (the main tail muscle, Figure 25) was primitively present in archosaurs and retained in the clades Dinosauria and Theropoda. Derived theropods (e.g., ornithomimids, deinonychosaurs, Archaeopteryx and birds) display features pointing to a decrease in caudofemoral musculature [44].

All dinosaurs usually had long tails that acted as counterweights to the body and bore most of the weight on their hindlegs, and therefore all of them could rear up, even the few that had arms that were longer than their legs [39].

Studying the tails from the mechanical viewpoint shows that the tails of sauropods do not exhibit noticeable adaptation to torsion and seem to have been moved more or less to a horizontal, extended posture [42]. In this respect, sauropod tails are similar to the necks of herbivorous cursorial mammals (mammals adapted specifically to run).

Myhrvold and Currie [45] modeled the tail of Apatosaurus louisae and estimated that it could reach supersonic velocities, consequently yielding noise analogous to the "crack" of a bullwhip. It seems that this was also feasible for other diplodocids, and possibly for unrelated sauropods like Mamenchisaurus and the dicraeosaurids, as suggested by similarity in tail structure. It was also proposed that the produced noise could have been used for defense, communication, intraspecific rivalry, or courtship, in which case supersonic "cracking" could have been a sexually dimorphic feature. Since the diplodocid whiplash tail was not well adapted as a direct-impact weapon, it follows that the tail-as-weapon hypothesis may be doubtful.

Some dinosaurs, like the sauropods Shunosaurus Iii and Omeisaurus tianfuensis, had club bearing tails. Also, ankylosaurid dinosaurs had an unusual tail club that has been assumed it was used actively as a weapon. Ankylosaurid tail clubs were composed of interlocking vertebrae that formed the handle, and large terminal osteoderms that formed the knob. Arbour [46] found that large knobs could generate sufficient force to break bone during impacts, something that could not be achieved by average and small knobs. The tail swinging behavior was feasible in ankylosaurids and could be used for defense or combat.

Other dinosaurs like stegosaurs, had spikes on their tails. McWhinney et al. [47] mention that the spikes probably were covered with a horny sheath that was not extended very far beyond the tip of the spike and were embedded by their bases in thick skin. Examination of a number of spikes, some of which were traumatized and infected, suggests that the primary purpose of the tail spikes was to actively be used as a weapon in defense and offence in combat.

Many ornithischians had bony rods, ossified tendons, embedded in the muscles of the back and tail that served to keep the body horizontal [48]. An example is the back and tail of Iguanodontia. Ossified tendons were tendons that turned to bone during life [49] (Figure 26). 


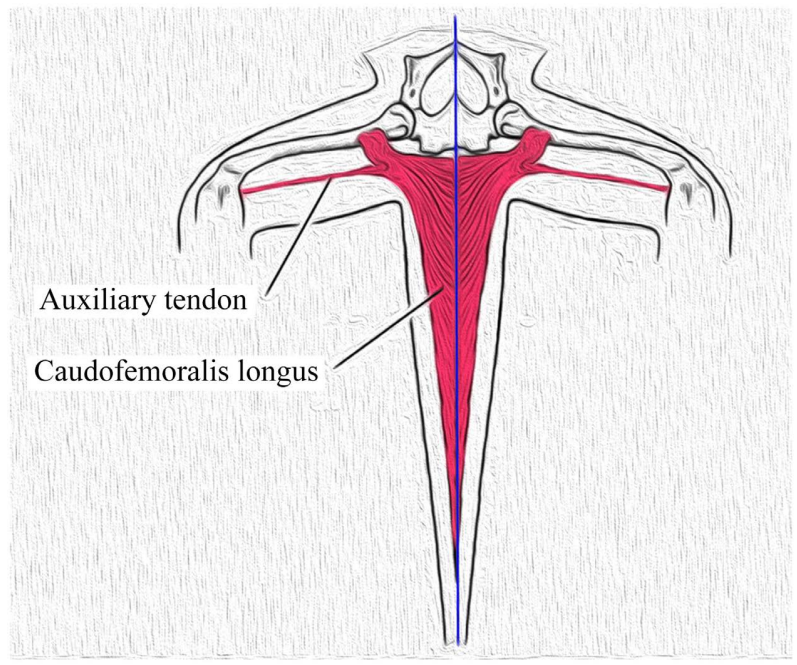

Figure 25. Iguana Caudofemoralis longus of the right hind limb (see also [44]).

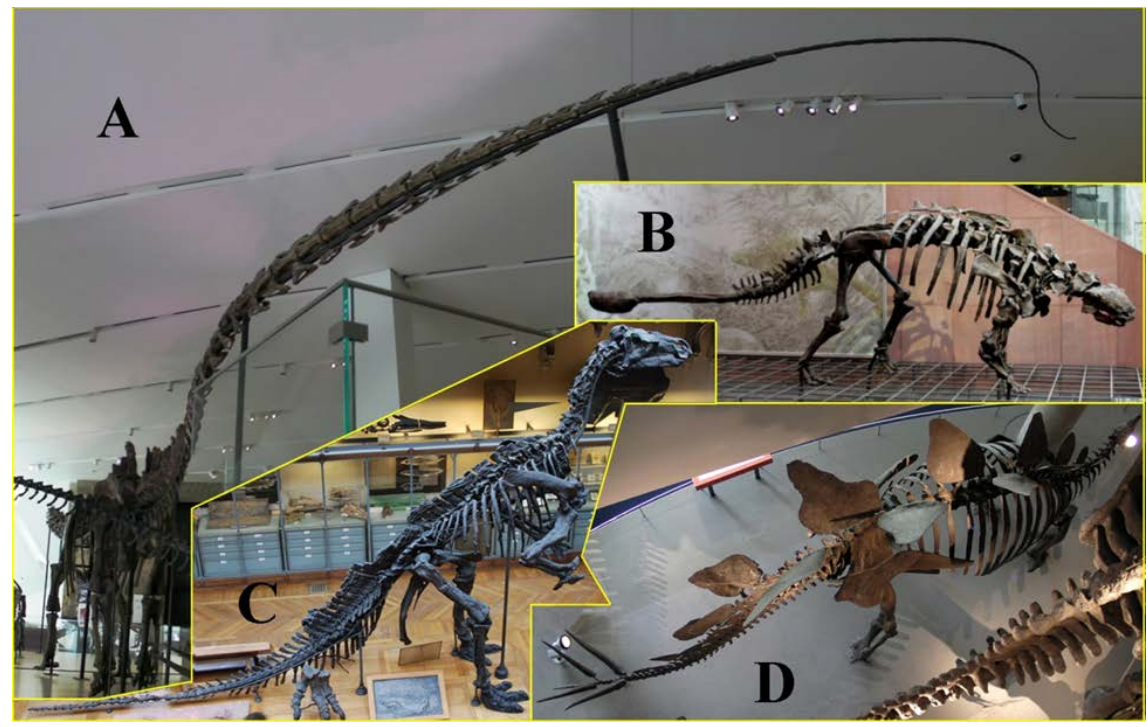

Figure 26. (A) A diplodocid with the whip tail-Royal Ontario Museum, Toronto, Canada. (B) An ankylosaurid baring a club tail-Senckenberg Nature Museum, Frankfurt, Germany. (C) Iguanodon with the stiff tail-National Museum of Natural History, Paris, France. (D) Stegosaurus with spikes at the end of its flexible tail-Naturalis Leiden, The Netherlands.

Most theropod tails, like the tails of Tyrannosaurus, had large muscular tails with muscle arrangements resembling those of modern reptiles. Digital muscle reconstructions, based on measurements of fossil specimens and dissections of modern reptiles, have shown that the $M$. caudofemoralis of many non-avian theropods was extremely large. This, together with long transverse processes, suggests that a large $M$. caudofemoralis is a basal characteristic of the group. As the $M$. caudofemoralis is the primary hind limb retractor, large $M$. caudofemoralis masses and the resulting contractile force and torque estimates indicate greater athleticism, in terms of overall cursoriality, balance, and turning agility 
[50]. Also, Carpenter [48] observes that the tetanurans, which include many of the famous theropods, like Velociraptor and Tyrannosaurus, had interlocking tail vertebrae that kept the tail stiff to stabilize the body while running.

\section{Posture of Amargasaurus Reconstruction}

Having in mind the above-given general knowledge, we will now proceed with specific details and decisions concerning our reconstruction of Amargasaurus.

The first step for any accurate reconstruction is to acquire a detailed knowledge of the dinosaur. Usually there will be a published paper in a scientific journal describing the remains of the dinosaur, from which one can start. For Amargasaurus Salgado and Bonaparte [51] give these details including scaled bone sketches.

Amargasaurus is a genus of dicraeosaurid sauropod dinosaur from the Early Cretaceous Period, around 130 mya, in what is now South America. It was small for a sauropod, reaching 10 meters in length. It was a quadruped herbivore with a long neck and a longer tail and it looked much like its relative Dicraeosaurus. However, this dinosaur presents a peculiarity, having two parallel rows of tall spines on its neck and back, which are taller than in any other known sauropod. Remains of this animal were found at the La Amarga Arroyo (which in Spanish means "the bitter creek") in Neuquén Province, Argentina (Figure 27). The name Amargasaurus was given to this dinosaur by Leonardo Salgado and José Bonaparte, in reference to La Amarga, in Neuquén Province and means "the lizard of La Amarga". The one named species ( $A$. cazaui) is named in honor of the man who discovered the site, Luis Cazau, a geologist.

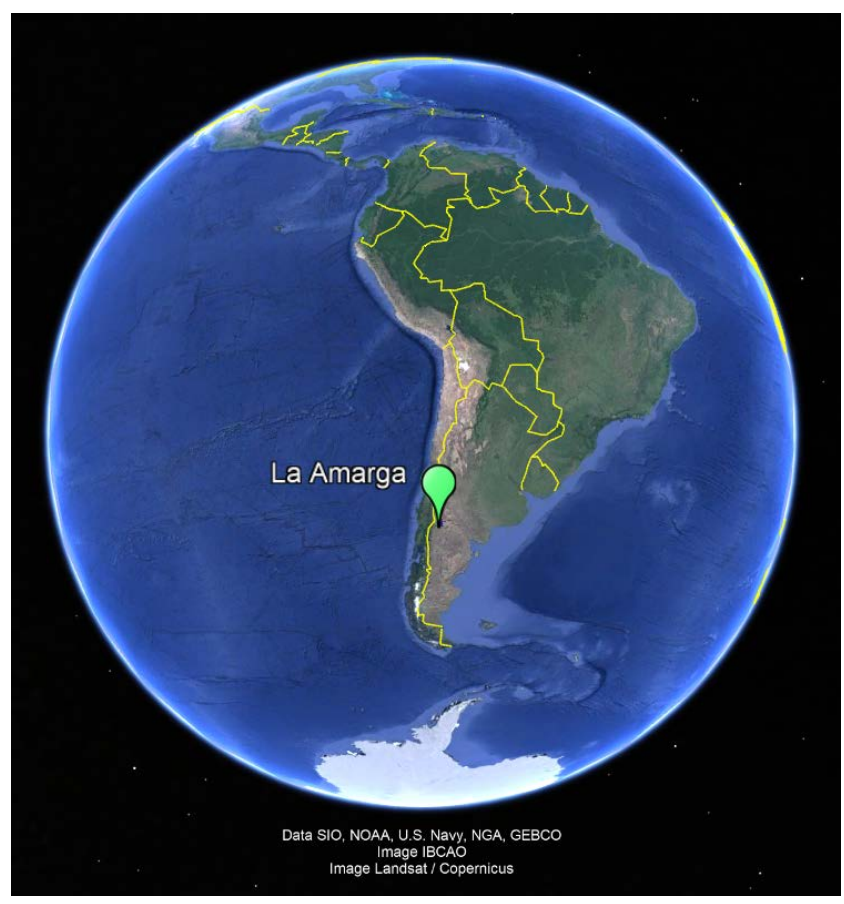

Figure 27. Amarga, neuquén province, argentina. South America (Google Earth). 
The specimen found is not complete, but a great part of the skeleton was recovered. The skeleton as reconstructed by Salgado and Bonaparte [51] is shown in Figure 28(A). There are also some other reconstructions, those of Salgado [52], Paul [39] and Hartman [54], shown in Figures 28(B)-(D). One can immediately observe that there are notable differences in the posture and the details of the skeleton in each reconstruction. These will be examined thoroughly during the various reconstruction stages.

The phylogenetic tree shows the inferred evolutionary relationships among various dinosaurs based upon similarities and differences in their physical or genetic characteristics. This tree facilitates one to find a characteristic posture of the animal according to the relevant studies of its order, family, genus, and so forth. A graphical representation of the phylogenetic tree with time spans and geographic locations is given in [54] and is shown in Figure 29.
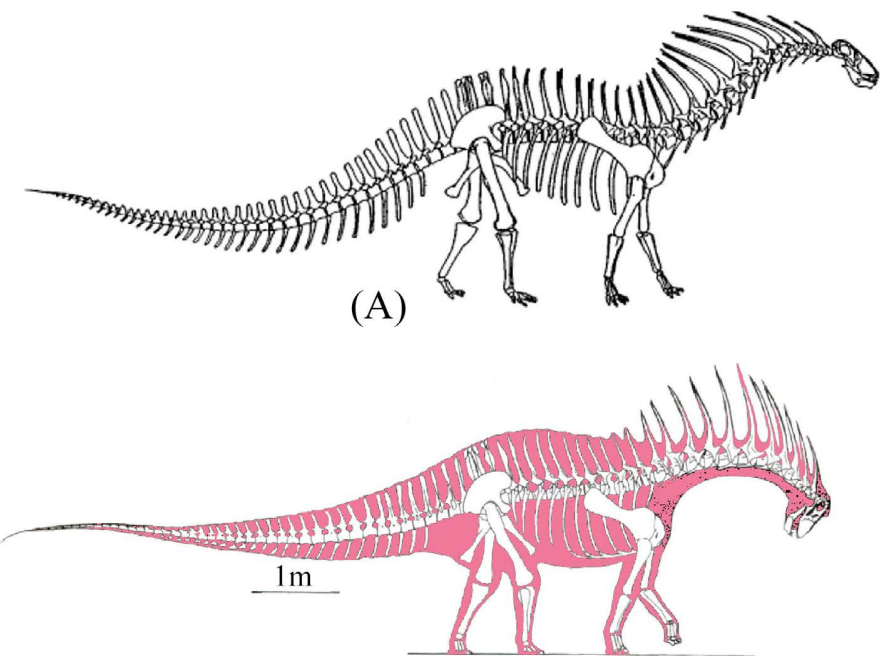

(B)
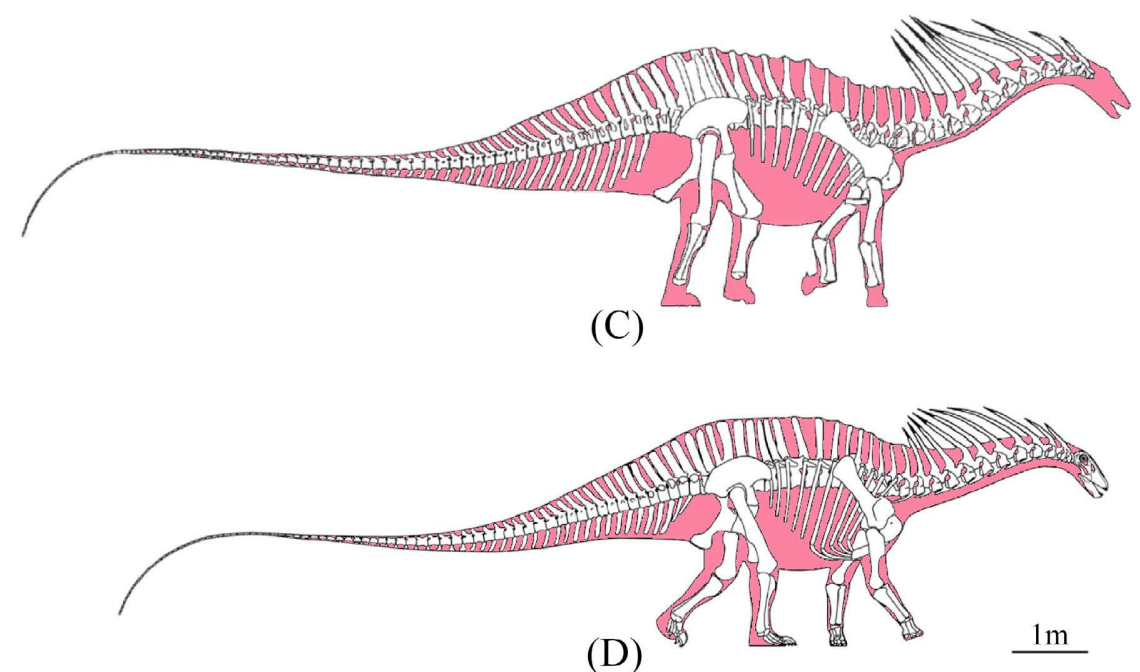

Figure 28. Amargasaurus cazaui. Reconstruction of the skeleton in lateral view as reconstructed by: (A) Salgado and Bonaparte [51], (B) Salgado [52], (C) Paul [39] and (D) Hartman [53]. All reconstructions redrawn to the same scale of the femoral length. 


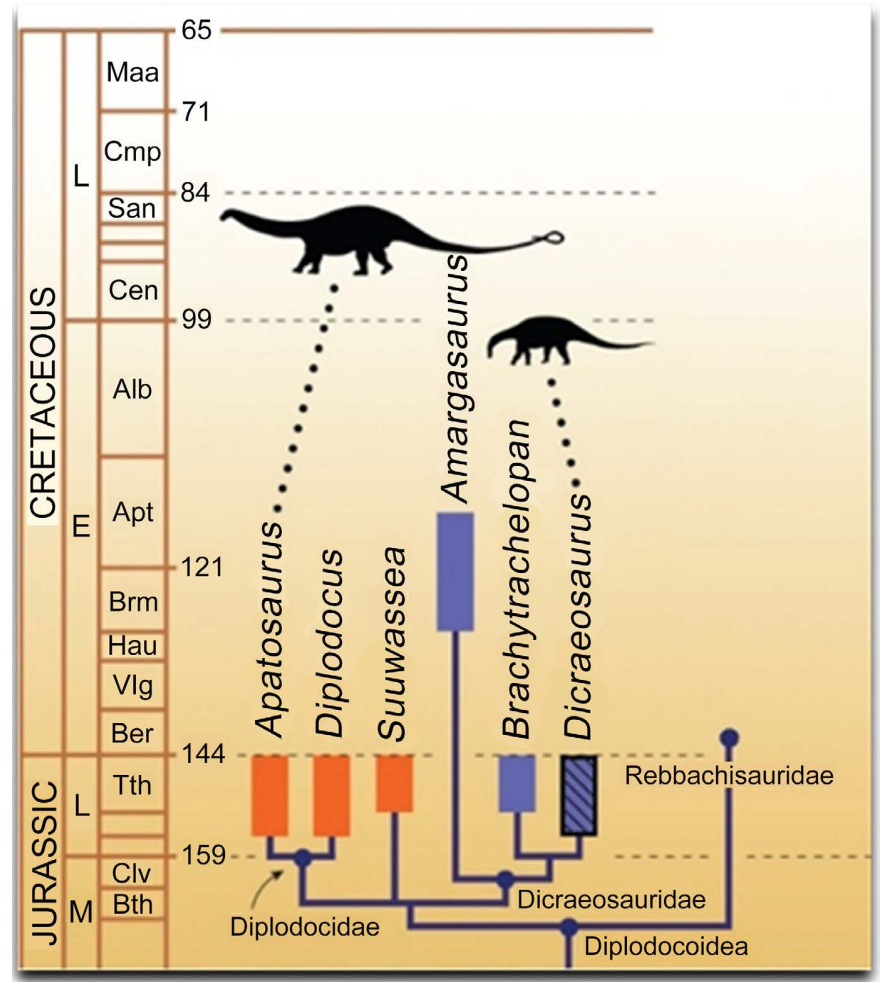

Figure 29. Calibrated phylogeny of diplodocoid sauropods. Color scheme: Laurasia (orange); Gondwana (blue); North America (solid orange); South America (blue); Africa (striped blue) (modified from [54]).

As is obvious, Amargasaurus posture resembles that of Dicraeosauridae and Diplodocidae with the long tails that could be used as a whip. From the four available reconstructions (Figure 28), those of Salgado and Bonaparte [51] and Salgado [52] do not seem to be very accurate according to the present knowledge and, therefore, will not be followed.

Another observation is that the animal had tall and robust vertebral spines over the hips (Figure 30(A)), which would allow the animal to rear up on hind legs. Such a position was given to the replica skeleton of Amargasaurus in the Victoria Museum, Melbourne, Australia [55] (Figure 30(B)). Reconstructions of the skeleton of Amargasaurus are found in permanent exhibitions but also in visiting ones, such as for example the visiting exhibition in the Victoria Memorial Museum of Ottawa in 2016 (Figure 31).

To select the best posture for the reconstruction of Amargasaurus, five simple three-dimensional models have been prepared (Figure 32) with various postures Amargasaurus would attain in life, in order to evaluate the advantages and disadvantages of each posture.

In Figure 32, (A) shows the animal walking leisurely, allowing the observer to appreciate the full length of the animal. In (B) the animal stands still in a more artistic posture bending the tail and neck left and right with the back feet vertically down. In (C) the animal is in panic raising the head-up, bends the back feet slightly and the tail is ready to strike. In (D) the animal bends the neck down in a 
way to repel the observer, while the tail is weaving. Finally, in (E) the body is raised up getting as high as it can.

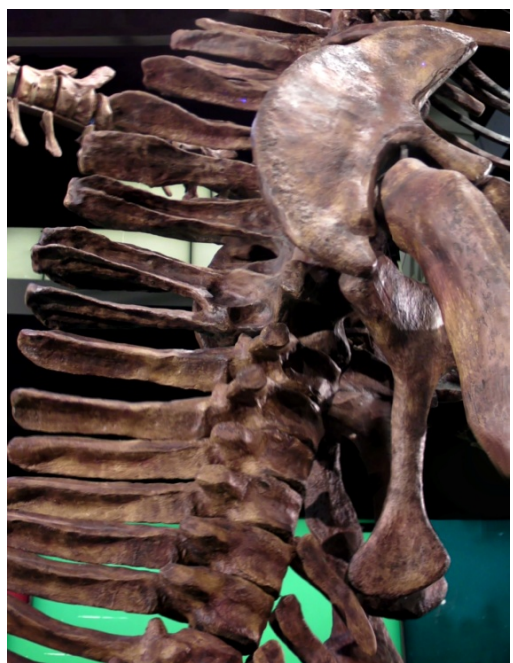

(A)

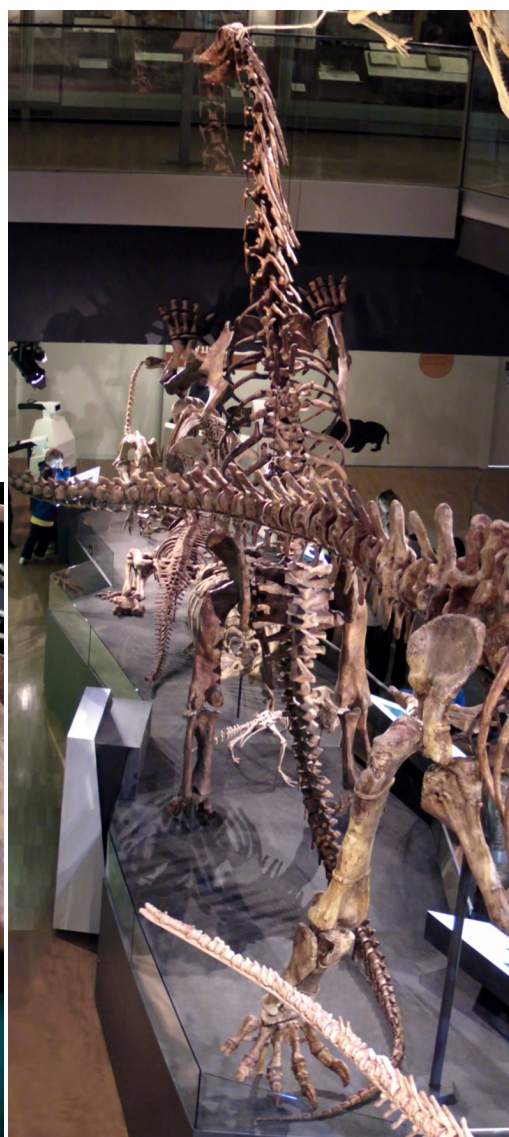

(B)

Figure 30. (A) Amargasaurus skeleton exhibiting tall and very robust vertebral spines over the hips that would allow the animal to rear up. (B) Amargasaurus skeleton reconstructed to rear up (Victoria Museum, Melbourne, Australia).

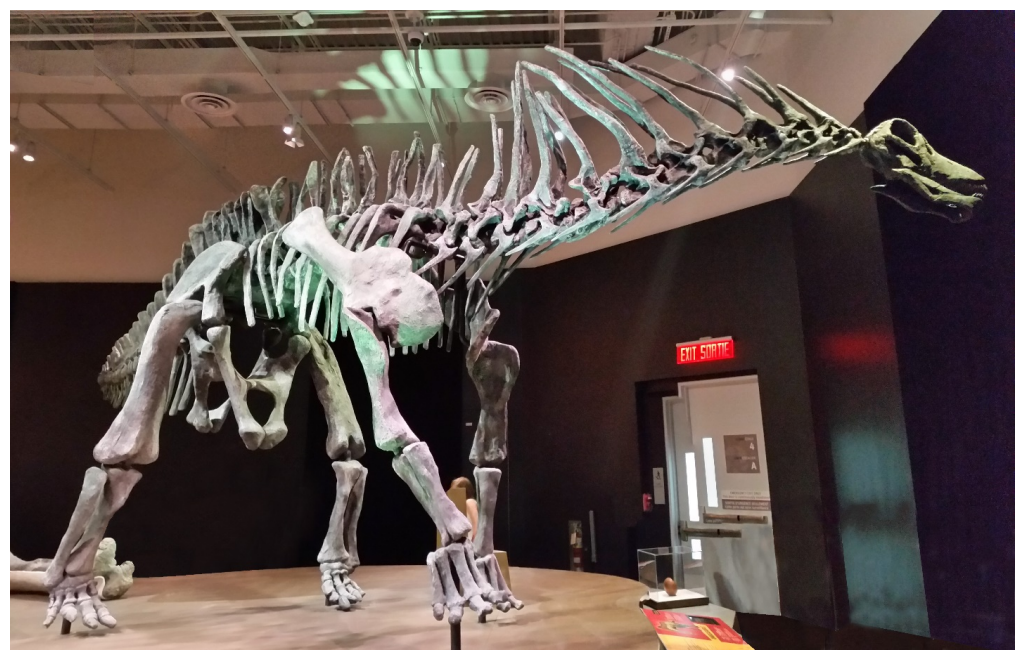

Figure 31. Amargasaurus skeleton exhibited in 2016, at the Victoria Memorial Museum of Ottawa. 

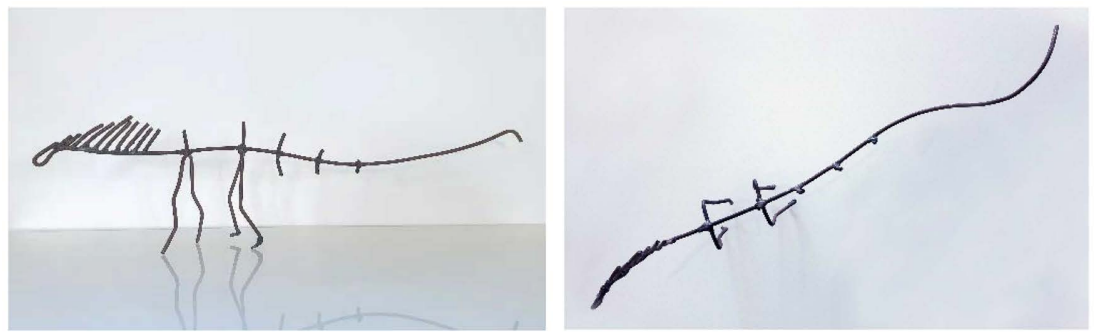

(A)
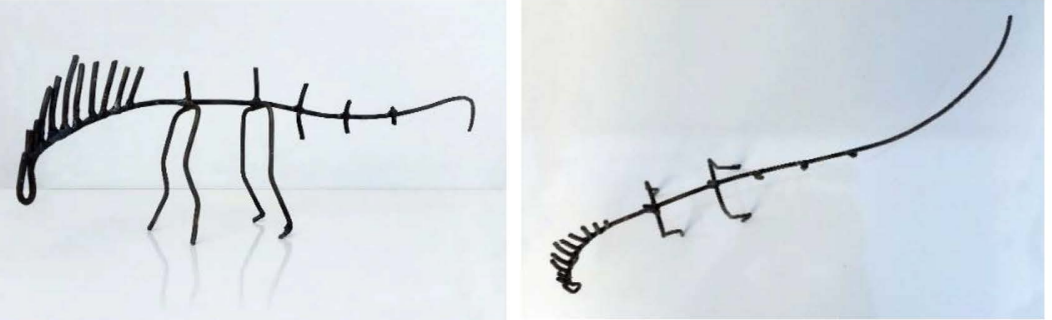

(B)
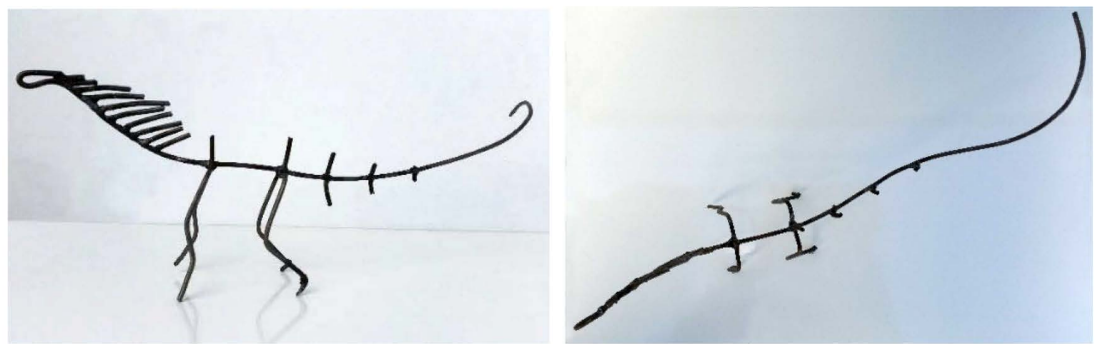

(C)
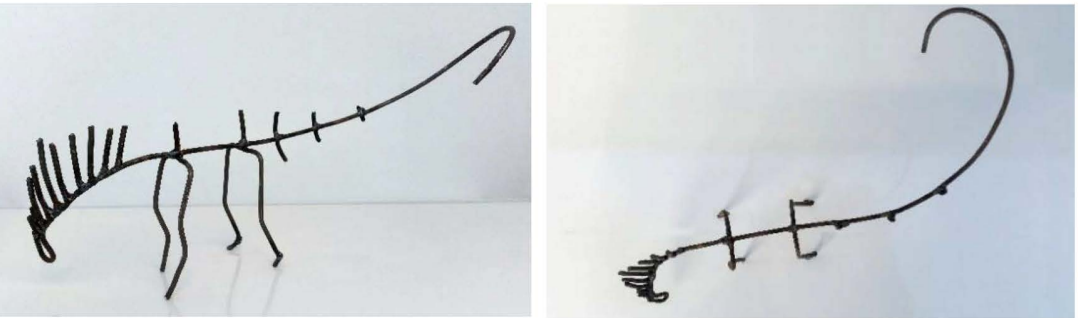

(D)
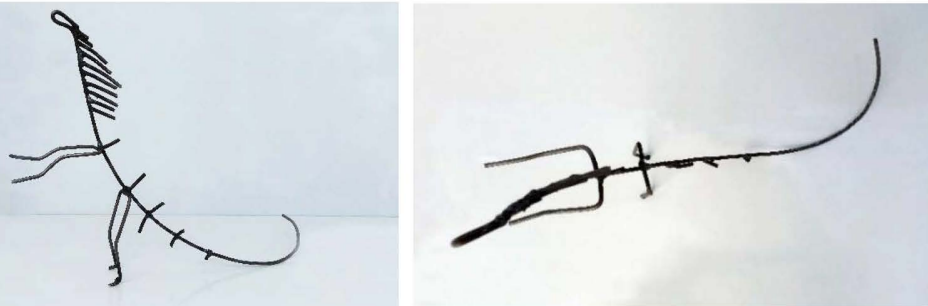

(E)

Figure 32. (A) shows the animal walking leisurely, allowing the observer to appreciate the full length of the animal. In (B) the animal stands still in a more artistic posture bending the tail and neck left and right with the back feet vertically down. In (C) the animal is in panic raising the head-up, bends the back feet slightly and the tail is ready to strike. In (D) the animal bends the neck down in a way to repel the observer, while the tail is weaving. Finally, in (E) the body is raised up getting as high as it can. 
Positions shown in (A) and (B) do not display much action, but they allow the observer to appreciate the full length of the animal. Also, because of a rather balanced weight, the reconstruction will not have difficulties in stability. The rest three postures are active and could impress the observer because of the flexibility of the animal. Reconstruction of the skeleton of (C) and (E) raises the neck and head of the animal very high, and the observer will not have a close view of these most interesting parts from ground level. An interesting position would be one that would allow the observer to see the head, which, though, should not be as close to the ground as in (D).

To sum it up, the choice of the posture is a matter of artistic taste; as such, posture (A) is selected for a restoration that will not have stability problems, will show the full length of the animal and the head of the animal will be at about the head level of the observer. During the construction stages of the full-scale animal, some alterations to the basic posture may be necessary in order to make the construction more appealing.

\section{Conclusions}

In this article specific details concerning the general postures held by dinosaurs during life are examined. The specific aim was to determine a probable posture for the reconstruction of Amargasaurus. Specifically, this paper (the second of the series) presents a number of general studies dealing with posture issues. A general description of Amargasaurus follows, and possible stances are modeled for taking the final decision on the posture of the reconstruction. Dinosaurs would move either bipedally or quadrupedally or even changing positions between the two.

Evidence for their movement is found in tracks and tracers, bones, etc. and can be deduced from their feeding habits and also by observing the movements of living birds and quadruped animals.

Ichnological and comparative biomechanical data show that theropods presented a locomotor behavior similar to modern birds. It was found that when the animals increased speed, the step-width decreased.

Scientists debate strongly on how the long necks of sauropods were held, with some arguing, with confidence, that articulating the axial elements in sauropods allows inference of their neutral or undeflected state, which is assumed to be the stance at which dinosaurs held their bodies during most of the time. Others believe that the short-necked diplodocoids held their necks nearly straight and horizontal, but for other groups many straightly restored sauropod necks show obvious misarticulations, or are based on vertebrae that are too distorted and incomplete to be reliably articulated. As opposed to the above opinions, there are scientists that present their own possible range, assuming that sauropods behaved in the same way as all extant amniote (mammals, turtles, squamates, crocodilians and birds) and they must have habitually held their necks extended maximally and their heads flexed maximally, so that the mid-cervical region was 
near vertical.

A review of tail tracks shows that they are rare, indicating that dinosaurs usually held their tails above ground. Dinosaur tail traces have been reported in the literature showing either resting traces or tail drag impressions for locomotion traces at low speeds. The abundance of tail traces is associated with bipedal, rather than quadrupedal, dinosaurs showing a reflection of behavior.

In bipedal dinosaurs, the long tail was acting as a counterbalance to the head and body that were held horizontal, with the femur sloping strongly forward to place the feet below the center of gravity that was ahead of the hip socket.

In the case of sauropods, no realistic idea seems to exist as to what the animals did with their tails, except keeping them horizontally to act as a counterweight for the neck.

The article presents basic details of Amargasaurus cazaui. A search in the literature has shown that there are four reconstructions of the skeletal remains of the animal in addition to the detailed study of the bones, on which one can be based to reconstruct Amargasaurus. There are also full reconstructions of the skeleton exhibited in various museums. For a beginning, the various positions of the animal were examined with the help of a model and one of the postures was selected for the reconstruction. Reconstruction details of Amargasaurus cazaui will be presented in future studies following the reconstruction stages.

\section{Conflicts of Interest}

The authors declare no conflicts of interest regarding the publication of this paper.

\section{References}

[1] Florides, G.A. and Christodoulides, P. (2021) On Dinosaur Reconstruction: An Introduction to Important Topics of Paleontology and Dinosaurs. Open Journal of Geology, 11, 525-571. https://doi.org/10.4236/ojg.2021.1110028

[2] Farlow, J.O., Gatesy, S.M., Holtz Jr., T.R., Hutchinson, J.R. and Robinson, J.M. (2000) Theropod Locomotion. American Zoologist, 40, 640-663. https://doi.org/10.1093/icb/40.4.640

[3] Alexander, R.M. (2006) Dinosaur Biomechanics. Proceedings of the Royal Society B: Biological Sciences, 273, 1849-1855. https://doi.org/10.1098/rspb.2006.3532

[4] Grossi, B., Iriarte-Díaz, J., Larach, O., Canals, M. and Vásquez, R.A. (2014) Walking like Dinosaurs: Chickens with Artificial Tails Provide Clues about Non-Avian Theropod Locomotion. PLoS ONE, 9, e88458.

https://doi.org/10.1371/journal.pone.0088458

[5] Tarsitano, S. (1983) Stance and Gait in Theropod Dinosaurs. Acta Palaeontologica Polonica, 28, 251-264.

[6] Carrier, D.R., Walter, R.M. and Lee, D.V. (2001) Influence of Rotational Inertia on Turning Performance of Theropod Dinosaurs: Clues from Humans with Increased Rotational Inertia. Journal of Experimental Biology, 204, 3917-3926. https://doi.org/10.1242/jeb.204.22.3917

[7] Bishop, P.J., Clemente, C.J., Weems, R.E., Graham, D.F., Lamas, L.P., Hutchinson, 
J.R., Rubenson, J., Wilson, R.S., Hocknull, S.A., Barrett, R.S. and Lloyd, D.G. (2017) Using Step Width to Compare Locomotor Biomechanics between Extinct, Non-Avian Theropod Dinosaurs and Modern Obligate Bipeds. Journal of the Royal Society Interface, 14, Article ID: 20170276. https://doi.org/10.1098/rsif.2017.0276

[8] Christian, A. (2002) Neck Posture and Overall Body Design in Sauropods. Fossil Record, 5, 271-281. https://doi.org/10.5194/fr-5-271-2002

[9] Christian, A., Peng, G., Sekiya, T., Ye, Y., Wulf, M.G. and Steuer, T. (2013) Biomechanical Reconstructions and Selective Advantages of Neck Poses and Feeding Strategies of Sauropods with the Example of Mamenchisaurus youngi. PLoS ONE, 8, e71172. https://doi.org/10.1371/journal.pone.0071172

[10] Stevens, K.A. (2013) The Articulation of Sauropod Necks: Methodology and Mythology. PLoS ONE, 8, e78572. https://doi.org/10.1371/journal.pone.0078572

[11] Witmer, L.M. and Ridgely, R.C. (2009) New Insights into the Brain, Braincase, and Ear Region of Tyrannosaurs (Dinosauria, Theropoda), with Implications for Sensory Organization and Behavior. The Anatomical Record: Advances in Integrative Anatomy and Evolutionary Biology: Advances in Integrative Anatomy and Evolutionary Biology, 292, 1266-1296. https://doi.org/10.1002/ar.20983

[12] Benoit, J., Legendre, L.J., Farke, A.A., Neenan, J.M., Mennecart, B., Costeur, L., Merigeaud, S. and Manger, P.R. (2020) A Test of the Lateral Semicircular Canal Correlation to Head Posture, Diet and Other Biological Traits in "Ungulate" Mammals. Scientific Reports, 10, 1-22. https://doi.org/10.1038/s41598-020-76757-0

[13] Taylor, M.P., Wedel, M.J. and Naish, D. (2009) Head and Neck Posture in Sauropod Dinosaurs Inferred from Extant Animals. Acta Palaeontologica Polonica, 54, 213-220. https://doi.org/10.4202/app.2009.0007

[14] Wedel, M.J. (2003) The Evolution of Vertebral Pneumaticity in Sauropod Dinosaurs. Journal of Vertebrate Paleontology, 23, 344-357. https://doi.org/10.1671/0272-4634(2003)023[0344:TEOVPI]2.0.CO;2

[15] Paul, G.S. (2017) Restoring Maximum Vertical Browsing Reach in Sauropod Dinosaurs. The Anatomical Record, 300, 1802-1825. https://doi.org/10.1002/ar.23617

[16] Thulborn, R.A. (1994) Ornithopod Dinosaur Tracks from the Lower Jurassic of Queensland. Alcheringa, 18, 247-258. https://doi.org/10.1080/03115519408619498

[17] Lockley, M.G. (1991) Tracking Dinosaurs: A New Look at an Ancient World CUP Archive. Cambridge University Press, Cambridge.

[18] Milner, A.R., Lockley, M.G., Kirkland, J.I. and Harris, J.D. (2006) A Large Collection of Well-Preserved Theropod Dinosaur Swim Tracks from the Lower Jurassic Moenave Formation, St. George, Utah. The Triassic-Jurassic Terrestrial Transition. New Mexico Museum of Natural History and Science Bulletin, 37, 315-328.

[19] Lockley, M.G., Foster, J.O. and Hunt, A.P. (1998) A Short Summary of Dinosaur Tracks and Other Fossil Footprints from the Morrison Formation. Modern Geology, 23, 277-290.

[20] Brett-Surman, M.K., Holtz, T.R. and Farlow, J.O. (2012) The Complete Dinosaur. 2nd Edition, Indiana University Press, Bloomington, 716.

[21] Dietrich, C. (2004) New Important Iguanodontid and Theropod Trackways of the Tracksite Obernkirchen in the Berriasian of NW Germany and Megatracksite Concept of Central Europe. Ichnos, 11, 215-228. https://doi.org/10.1080/10420940490444924

[22] Paul, G.S. (1989) The Science and Art of Restoring the Life Appearance of Dinosaurs and Their Relatives. In: Czerkas, S. and Olson, E., Eds., Dinosaurs Past and 
Present Vol. II, NHM of Los Angeles County in Association with University of Washington Press, Los Angeles, 5-49.

[23] Sereno, P.C. (1999) The Evolution of Dinosaurs. Science, 284, 2137-2147. https://doi.org/10.1126/science.284.5423.2137

[24] Lee, Y.-N., Barsbold, R., Currie P.J., Kobayashi Y., Lee, H.-J., Godefroit, P., Escuillié, F. and Chinzorig, T. (2014) Resolving the Long-Standing Enigmas of a Giant Ornithomimosaur Deinocheirus mirificus. Nature, 515, 257-260.

http://www.nature.com/doifinder/10.1038/nature13874

http://www.youtube.com/watch?v=zNivMG22PB4

https://doi.org/10.1038/nature13874

[25] Wilson, J.A. (2005) Overview of Sauropod Phylogeny and Evolution. In: Curry Rogers, K. and Wilson, J., Eds., The Sauropods. Evolution and Paleobiology, University of California Press, Berkeley, 15-49. https://doi.org/10.1525/california/9780520246232.003.0002

[26] Falkingham, P.L., Bates K.T. and Farlow, J.O. (2014) Historical Photogrammetry: Bird's Paluxy River Dinosaur Chase Sequence Digitally Reconstructed as It Was prior to Excavation 70 Years Ago. PLoS One, 9, e93247.

https://doi.org/10.1371/journal.pone.0093247

[27] Bonnan, M.F. (2003) The Evolution of Manus Shape in Sauropod Dinosaurs: Implications for Functional Morphology, Forelimb Orientation, and Phylogeny. Journal of Vertebrate Paleontology, 23, 595-613. https://doi.org/10.1671/A1108

[28] Lockley, M.G., Farlow, J.O. and Meyer, C.A. (1994) Brontopodus and Parabrontopodus ichnogen. nov. and the Significance of Wide- and Narrow-Gauge Sauropod Trackways. Gaia, 10, 135-145.

[29] Wilson, J.A. and Carrano, M.T. (1999) Titanosaurs and the Origin of "Wide-Gauge" Trackways: A Biomechanical and Systematic Perspective on Sauropod Locomotion. Paleobiology, 25, 252-267. https://doi.org/10.1017/S0094837300026543

[30] Hartman, S. (2016) Gauging Stance in "Wide-Gauge" Sauropods.

http://www.skeletaldrawing.com/home/2011/11/gauging-stance-in-wide-gauge-saur opods.html

[31] González Riga, B.J. (2011) Speeds and Stance of Titanosaur Sauropods: Analysis of Titanopodus Tracks from the Late Cretaceous of Mendoza. Argentina Anais da Academia Brasileira de Ciências, 83, 1-12. https://www.scielo.br/j/aabc/a/N6BDfCcXdfKCnzrxGkgrMXC/?format=pdf\&lang= en https://doi.org/10.1590/S0001-37652011005000002

[32] Fowler, D.W. and Hall, L.E. (2011) Scratch-Digging Sauropods. Revisited Historical Biology, 23, 27-40. https://doi.org/10.1080/08912963.2010.504852

[33] Wright, J.L. (2005) Steps in Understanding Sauropod Biology: The importance of Sauropod Tracks. In: Curry Rogers, K.A. and Wilson, J.A., Eds., The Sauropods. Evolution and Paleobiology, University of California Press, Berkeley, 252-280. https://doi.org/10.1525/california/9780520246232.003.0010

[34] Sellers, W.I., Margetts, L., Coria, R.A. and Manning, P.L. (2013) March of the Titans: The Locomotor Capabilities of Sauropod Dinosaurs. PLOS ONE, 8, e78733. https://doi.org/10.1371/journal.pone.0078733

[35] Bakker, R.T. (1986) The Dinosaur Heresies. William Morrow and Company Inc., New York, 192.

[36] Florides, G.A. (2018) Visit. Australia Museum, Sydney.

[37] Seymour, R.S. and Lillywhite, H.B. (2000) Hearts, Neck Posture and Metabolic In- 
tensity of Sauropod Dinosaurs. Proceedings of the Royal Society of London, Series $B, 267,1883-1887$. https://doi.org/10.1098/rspb.2000.1225

[38] Stevens, K.A. and Parrish, J.M. (2005) 10. Neck Posture, Dentition, and Feeding Strategies in Jurassic Sauropod Dinosaurs. In: Thunderlizards. The Sauropodomorph Dinosaurs, Indiana University Press, Bloomington, 212-232.

[39] Paul, G.S. (2010) The Princeton Field Guide to Dinosaurs. Princeton University Press, Princeton, 188. https://doi.org/10.1515/9781400836154

[40] Taylor, M.P. (2014) Quantifying the Effect of Intervertebral Cartilage on Neutral Posture in the Necks of Sauropod Dinosaurs. PeerJ, 2, e712.

https://doi.org/10.7717/peerj.712

[41] Marugán-Lobón, J., Chiappe, L.M. and Farke, A.A. (2013) The Variability of Inner Ear Orientation in Saurischian Dinosaurs: Testing the Use of Semicircular Canals as a Reference System for Comparative Anatomy. PeerJ, 1, e124. https://doi.org/10.7717/peerj.124

[42] Preuschoft, H. and Klein, N. (2013) Torsion and Bending in the Neck and Tail of Sauropod Dinosaurs and the Function of Cervical Ribs: Insights from Functional Morphology and Biomechanics. PLoS ONE, 8, e78574.

https://doi.org/10.1371/journal.pone.0078574

[43] Kim, J.Y. and Lockley, M.G. (2013) Review of Dinosaur Tail Traces. Ichnos, 20, 129-141. https://doi.org/10.1080/10420940.2013.817405

[44] Gatesy, S.M. (1990) Caudofemoral Musculature and the Evolution of Theropod Locomotion. Paleobiology, 16, 170-186. https://doi.org/10.1017/S0094837300009866

[45] Myhrvold, N.P. and Currie, P.J. (1997) Supersonic Sauropods? Tail Dynamics in the Diplodocids. Paleobiology, 23, 393-409.

https://doi.org/10.1017/S0094837300019801

[46] Arbour, V.M. (2009) Estimating Impact Forces of Tail Club Strikes by Ankylosaurid Dinosaurs. PLoS ONE, 4, e6738. https://doi.org/10.1371/journal.pone.0006738

[47] McWhinney, L.A., Rothschild, B.M. and Carpenter, K. (2001) Posttraumatic Chronic Osteomyelitis in Stegosaurus Dermal Spikes. In: Carpenter, K., Ed., The Armored Dinosaurs, Indiana University Press, Bloomington, 141-156.

[48] Carpenter, K. (2001) Dinosauria (Dinosaurs) eLS, Wiley Online Library. https://doi.org/10.1038/npg.els.0001545

[49] Norman, D.B. (2004) Basal Iguanodontia. In: Weishampel, D.B., Dodson, P. and Osmólska, H., Eds., The Dinosauria, 2nd Edition, University of California Press, Berkeley, 413-437. https://doi.org/10.1525/california/9780520242098.003.0022

[50] Persons, W.S. and Currie, P.J. (2011) The Tail of Tyrannosaurus: Reassessing the Size and Locomotive Importance of the $M$. caudofemoralis in Non-Avian Theropods. The Anatomical Record: Advances in Integrative Anatomy and Evolutionary Biology, 294, 119-131. https://doi.org/10.1002/ar.21290

[51] Salgado, L. and Bonaparte, J.F. (1991) A New Dicraeosaurid Sauropod, Amargasaurus cazaui Gen. Et Sp. Nov., from the La Amarga Formation, Neocomian of Neuquén Province, Argentina. Ameghiniana, 28, 333-346.

https://www.google.com/url?sa=t\&rct=j\&q=\&esrc=s\&source=web\&cd=\&ved=2ahUK Ewij0LKzlc30AhUTi1wKHXpYD-gQFnoECAQQAQ\&url=https\%3A\%2F\%2Fpaleo glot.org\%2Ffiles\%2Fsalgado\%26bona_91.pdf\&usg=AOvVaw3cPGdoUea4ZsWASa9 $\underline{\text { ZExzw }}$

[52] Salgado, L. (1999) The Macroevolution of the Diplodocimorpha (Dinosauria; Sau- 
ropoda): A Developmental Model. Ameghiniana, 36, 203-216.

[53] Hartman, S. (2014).

http://www.skeletaldrawing.com/sauropods-and-kin/amargasaurus

[54] Sereno, P.C., Wilson, J.A., Witmer, L.M., Whitlock, J.A., Maga, A., Ide, O. and Rowe, T.A. (2007) Structural Extremes in a Cretaceous Dinosaur. PLoS ONE, 2, e1230. https://doi.org/10.1371/journal.pone.0001230

[55] Victoria Museum, Melbourne, Australia (2021). https://museumsvictoria.com.au/our-museums 